\title{
Growth, Development and Genetic Characteristics of Physarum polycephalum Amoebae Able to Grow in Liquid, Axenic Medium
}

\author{
By JENNIFER DEE, ${ }^{*}{ }^{*}$ JENNIFER L. FOXON ${ }^{1}$ AND \\ ROGER W. ANDERSON ${ }^{2}$ \\ ${ }^{1}$ Department of Genetics, University of Leicester, Leicester LEI 7RH, UK \\ ${ }^{2}$ Department of Genetics, University of Sheffield, Sheffield S10 2TN, UK
}

(Received 14 November 1988; revised 3 February 1989; accepted 2 March 1989)

\begin{abstract}
Amoebae from natural isolates of Physarum polycephalum, unlike the plasmodial phase, are unable to grow in axenic medium. A mutant strain of amoebae, CLd-AXE, can be cultured in the liquid, semi-defined medium used for plasmodial culture but lacks some of the properties required for studies of development and gene expression. From crosses of CLd-AXE with wildtype amoebae, new amoebal strains able to grow in axenic medium have been isolated; some of these can also undergo the reversible amoeba-flagellate transformation and apogamic plasmodium development in axenic conditions. Amoebae maintained in active growth in liquid culture for several months showed little change in their properties. Subcultures made with diluted inocula indicated that the same growth rate was achieved even when single amoebae were inoculated in liquid medium. All strains produced colonies with high efficiency when replated on bacterial lawns. Measurements of DNA content by flow cytometry indicated that the majority of amoebae in liquid cultures were haploid. Homozygous diploid amoebae constructed from one strain grew less well than the haploid cells. Genetic analysis of crosses suggested that amoebae able to grow in liquid axenic medium fell into one major phenotypic class with respect to growth rate, and that mutation at only one or two loci was necessary to allow amoebae to grow in axenic medium. Diploid, heterozygous amoebae constructed by mating a mutant with a wildtype strain were unable to grow in axenic medium, indicating that at least one of the putative axe alleles was recessive.
\end{abstract}

\section{INTRODUCTION}

Although the plasmodial phase of Physarum polycephalum can readily be cultured on semidefined liquid or agar-based media, amoebae derived from natural isolates of this slime mould cannot be grown in such conditions. For many years, the plasmodium was the main stage used for biochemical studies, for example of the cell cycle and cell motility, and the amoebal stage was used mainly in genetic analysis, for which cultures on bacterial lawns were satisfactory. When the culture of $P$. polycephalum amoebae in liquid axenic media was eventually achieved, it was found that the amoebae in culture were genetically different from those originally inoculated and that normal, wild-type amoebae could not be cultured in the conditions used (Goodman, 1972; McCullough \& Dee, 1976; McCullough et al., 1978). Thus, new strains, carrying an unknown number of mutant alleles, had been selected unintentionally during the prolonged attempts to culture the amoebae in axenic medium. The new strains facilitated biochemical studies of the amoebae, and one strain in particular, CLd-AXE, (derived from the strain CLd) has been widely used in recent research on Physarum, for example, in the analysis of microtubule organization (Roobol et al., 1980; Havercroft \& Gull, 1983) and tubulin gene expression (Burland et al., 1983).

Abbreviation: CIPC, isopropyl $N$-(3-chlorophenyl)carbamate. 
Extensive differences in gene expression between Physarum amoebae and plasmodia have been demonstrated in several laboratories by the screening of cDNA libraries (Dove et al., 1986; Sweeney et al., 1987). Apogamic strains of $P$. polycephalum provide a convenient system in which to study changes in gene expression because development from amoeba to plasmodium occurs in single haploid cells without change in nuclear DNA content (Cooke \& Dee, 1974; Gorman et al., 1979). Cytological and cinematographic analyses of the apogamic strain CL, cultured on bacteria, have shown that commitment to plasmodium development occurs in uninucleate cells which undergo an extended cell cycle before the nuclear divisions, unaccompanied by cytokinesis, that give rise to the multinucleate, syncytial plasmodium (Anderson et al., 1976; Bailey et al., 1987). During this cell cycle, the amoebae lose the ability to form flagellated cells and by the end of the cycle, they have acquired the ability to undergo the intranuclear mitosis characteristic of plasmodia (Blindt, 1987; Blindt et al., 1986; Gull et al., 1985). For analysis of the molecular changes underlying these events, it is clearly important that amoebae should be cultured in axenic media throughout their development to plasmodia. CLdAXE is not a suitable strain for such an analysis, however, since it carries at least one mutation ( $n p f C$ ) blocking apogamic plasmodium development. This strain is unsuitable for other important areas of research also: the amoebae have not been induced to undergo the amoebaflagellate transformation in axenic conditions, and it has been reported from several laboratories (see Dee, 1986) that CLd-AXE amoebae which were originally haploid (McCullough et al., 1978), have become diploid during culture, making them unsuitable for the isolation of mutants or genetic transformants. Other genetic changes also apparently occurred in CLd-AXE during culture; unlike CLd, it could rarely be induced to form 'selfed' plasmodia by reversion of the $n p f C$ mutation, and the plasmodia obtained were often morphologically abnormal and failed to sporulate. It was feared that some or all of these abnormalities might be associated with the ability to grow in liquid axenic media, but it was also possible that they might simply be due to mutations accumulated during long periods of culture.

The main aim of the work reported in this paper was to isolate new strains of $P$. polycephalum amoebae able to grow in axenic medium and having characteristics suitable for the various areas of research currently being pursued in this organism. Genetic analysis of crosses involving CLdAXE had originally suggested that the ability to grow in axenic medium was conferred by mutations at two unlinked loci; when CLd-AXE was crossed with some laboratory strains, about one-quarter of the progeny inherited the ability to grow in axenic medium (McCullough $e t$ al., 1978; J. Gorman, personal communication). Later analyses gave erratic results, however, suggesting that the basis of growth in axenic medium might be more complex than originally supposed (Chainey, 1981; T. G. Burland, personal communication; Dee, 1986). Renewed attempts to derive useful strains from crosses of CLd-AXE suggested that, with some modifications of procedure, this approach might be successful, and it was therefore adopted in preference to the isolation of new mutant strains. In view of the reported instability of CLd$\mathrm{AXE}$, and doubts whether growth in axenic medium was compatible with apogamic development or flagellation, an important second aim was to test the properties and stability of any new strains during prolonged culture in liquid axenic media. A full analysis of the number and action of the genes responsible for growth in axenic medium was not among the aims of this work, but it was hoped that genetic analysis of crosses involving the new strains would put future strain construction on a firm basis.

\section{METHODS}

Loci. matA, amoebal mating-type: alleles matA1, matA2, matA3 etc. control heterothallic plasmodium formation (also designated $m t-1$ etc.; Dee, 1966); allele mat $A h(=m t-h$; Wheals, 1970) confers the ability to form haploid plasmodia within amoebal clones (apogamic development; Anderson et al., 1976). Unlike heterothallic plasmodium formation, apogamic development is inhibited by high temperature $\left(29-30^{\circ} \mathrm{C}\right)$. The matA locus has been shown to control the development rather than the formation of zygotes in heterothallic crosses (Youngman $e t$ al., 1979, 1981).

mat $B$, amoebal mating-type: alleles matB1, matB2 etc. affect the frequency of zygote formation (Youngman et al., 1979, 1981). Crossing can occur between strains carrying the same mat $B$ allele but occurs more efficiently between strains carrying different alleles. 


\section{Table 1. Strains used}

\begin{tabular}{ll}
\multicolumn{1}{c}{ Strain } & \multicolumn{1}{c}{ Reference or origin } \\
CL & Cooke \& Dee (1974) \\
CLd & Cooke \& Dee (1974) \\
CLd-AXE & McCullough et al. $(1978) \dagger$ \\
LU203 & Dee (1978) \\
LU213 & LU203 $\times$ LU862 \\
LU299 & CLd-AXE $\times$ LU213 \\
LU352 & CLd-AXE $\times$ LU213 \\
LU353 & CLd-AXE $\times$ LU213 \\
LU359 & CLd-AXE $\times$ RA272 \\
LU381 & Dee \& Anderson (1984) \\
LU412 & LU412 $\times$ LU860 \\
LU481 & npfC + revertant of LU352 \\
LU600 & Dee (1978) \\
LU860 & Anderson \& Dee (1977) \\
LU862 & Kawano et al. $(1987)$ \\
OX112 & Kawano et al. $(1987)$ \\
RA272 & LU352/OX112 mixtures \\
RA681-683 & (see Results) \\
& LU352 treated with CIPC \\
RA684-685 & OX112 treated with CIPC \\
RA686-687 &
\end{tabular}

\author{
Genotype* \\ matAh matB1 fusA2 \\ mat Ah npfC matB1 fus $A 2$ \\ matAh npfC matB1 fusA2 axe \\ matA3 matB3 fusAl leuAl \\ matAI matB3 fusAl leuAI \\ matAh npfC matB3 fusAl axe \\ matA3 matB1 fusA2 leuA1 axe \\ matA3 matB3 fusA2 axe \\ matA4 matB2 matC2 fusAl whiAl axe \\ matA1 matB1 fusA2 whiA1 leuA1 lysB2 \\ matAh matB3 fusAl axe \\ matA3 matB3 fus A1 \\ matA2 matB1 matC2 fusA2 fusC2 whiA1 \\ matA4 matB2 matC2 fusA1 whiAl \\ Heterozygous diploid amoebae (see \\ genotypes of LU352 \& OX112) \\ Homozygous diploid amoebae (see LU352) \\ Homozygous diploid amoebae (see OX112)
}

* Genotypes are given only for strains mentioned in the Results and Discussion. Except where specified, all strains carried matCl, $\mathrm{fusCl}$ and wild-type alleles at all other loci listed in Methods.

$\dagger$ Obtained from the McArdle Laboratory, Madison, Wis., USA.

matC, amoebal mating-type: alleles matC1, matC2 etc. influence the maximum $\mathrm{pH}$ at which crossing will occur; heteroallelic combinations can cross at higher $\mathrm{pH}$ than homoallelic (Kawano et al., 1987). Formerly called imz (Shinnick et al., 1978).

$n p f C$, no plasmodium formation; closely linked to mat $A$; plasmodium formation is prevented in amoebae of genotype mat Ah npfC (Anderson \& Dee, 1977; Anderson, 1979). Revertant $n p f C^{+}$mutations in matAh npfC amoebal colonies result in a low frequency of apogamic plasmodium formation; progeny of these plasmodia form stable mat $A h n p f C^{+}$amoebal clones which exhibit efficient apogamic plasmodium formation.

fus $A$, fusC, plasmodial fusion loci; alleles fus $A 1$ and fusA2 are co-dominant; fusion does not occur between plasmodia carrying different fusA alleles (Poulter \& Dee, 1968; Dee, 1982). Allele fusC2 is dominant to fusC1; fusion occurs only between plasmodia that are phenotypically identical at this locus (Adler \& Holt, 1974b).

leuA, recessive allele leuAl causes leucine requirement in plasmodia (Cooke \& Dee, 1975).

lys $B$, recessive allele $l y s B 2$ causes lysine requirement in plasmodia (Dee, 1982).

whiA, recessive allele whiAl causes white instead of the wild-type yellow plasmodia (Anderson, 1977).

axe, mutations confer on amoebae the ability to grow in liquid, axenic medium. Two hypothetical unlinked loci were designated axeA and axeB by McCullough et al. (1978) but were not separately identified.

Strains. Table 1 gives the origin and genotypes of amoebal strains. Nomenclature follows Anderson $e t$ al. (1986).

Media. LIA (liver infusion agar). Liver infusion stock solution $(40 \mathrm{ml})$ and $10 \mathrm{ml}$ sodium phosphate buffer $(0.5 \mathrm{M}, \mathrm{pH} 6.8)$ added to each litre of molten $1.5 \%(\mathrm{w} / \mathrm{v})$ agar (Biolife or Sterilin) just before pouring. Liver infusion stock solution: $100 \mathrm{~g}$ desiccated liver (Oxoid product no. L26) per litre of distilled water. For cultures on FKB (see below), penicillin ( 250 units $1^{-1}$ ) and streptomycin $\left(250\right.$ units $1^{-1}$ ) were added to the molten LIA before pouring.

SBS (standard bacterial suspension). Escherichia coli inoculated on a $9 \mathrm{~cm}$ plate of Nutrient Agar, incubated overnight and washed off in $5 \mathrm{ml}$ distilled water.

FK B (formalin-killed bacteria). Suspension prepared as in Dee (1986), and diluted 1:1 with distilled water before use.

SDM (semi-defined medium) liquid. This contained (per litre of distilled water): $10.0 \mathrm{~g}$ glucose, $10.0 \mathrm{~g}$ Soytone (Difco-Bacto), $2.0 \mathrm{~g} \mathrm{KH} \mathrm{KH}_{2} \mathrm{PO}_{4}, 1.35 \mathrm{~g} \mathrm{CaCl}_{2} .6 \mathrm{H}_{2} \mathrm{O}, 0.6 \mathrm{~g} \mathrm{MgSO}_{4} .7 \mathrm{H}_{2} \mathrm{O}, 0.039 \mathrm{~g} \mathrm{FeCl} .4 \mathrm{H}_{2} \mathrm{O}, 0.034 \mathrm{~g}$ $\mathrm{ZnSO}_{4} .7 \mathrm{H}_{2} \mathrm{O}, 3.54 \mathrm{~g}$ citric acid, $0.224 \mathrm{~g} \mathrm{Na}_{2}$ EDTA, $0.005 \mathrm{~g}$ biotin and $0.04 \mathrm{~g}$ thiamin. The $\mathrm{pH}$ was adjusted to 4.6 with $20 \%(\mathrm{w} / \mathrm{v}) \mathrm{NaOH}$ and the medium sterilized in an autoclave at 15 p.s.i. for $15 \mathrm{~min}$. Haematin $(1 \mathrm{ml} ; 0.05 \%$ in $1 \% \mathrm{NaOH}$ ) was added to $100 \mathrm{ml}$ immediately before use.

SDM agar. Molten 3\% (w/v) agar mixed with an equal volume of SDM liquid just before use.

DSDM (dilute SDM) agar; $62.5 \mathrm{ml} \mathrm{SDM} \mathrm{liquid} \mathrm{per} \mathrm{litre} \mathrm{of} 1.5 \%$ agar.

DSDM agar + citrate. DSDM containing $3 \mathrm{ml}$ sodium citrate buffer (1 M; pH 5.0) per litre.

DSDM/LIA. DSDM agar containing $40 \mathrm{ml}$ liver infusion stock solution per litre. 
Culture and re-cloning of amoebae on bacterial lawns. For routine culture, amoebae were inoculated on LIA (with a toothpick or in suspension in water) together with $0.1 \mathrm{ml}$ SBS per $9 \mathrm{~cm}$ Petri dish. The suspensions were spread with a bent glass-rod. For re-cloning, a dilute amoebal suspension was used to give single colonies in the bacterial lawn. Amoebal cultures were incubated at $26^{\circ} \mathrm{C}$ except mat $A h$ or mat $A h$ npfC strains, which were incubated at 29 $30{ }^{\circ} \mathrm{C}$ to inhibit plasmodium formation, after an initial period of 1 or $2 \mathrm{~d}$ at $26^{\circ} \mathrm{C}$ to allow the amoebae to excyst and begin growth. For re-plating amoebae from liquid axenic medium onto bacterial lawns, dilutions were made in SDM and the amoebal suspension was not allowed to mix with the SBS until the plates were spread. In replating experiments, best results were obtained with LIA containing $2 \%(\mathrm{w} / \mathrm{v})$ Sterilin agar poured into plates $4 \mathrm{~d}$ before use, so that the agar surface was firm and became dry soon after (but not during) spreading.

Storage of amoebal strains. Amoebae cultured on live E. coli were stored at $4{ }^{\circ} \mathrm{C}$ after a period of incubation long enough for cysts to form in the amoebal colonies; amoebae cultured on FKB were not stored because previous results suggested that they do not form viable cysts. For long-term storage, amoebal cultures on live $E$. coli were frozen by the method described in detail by Dee (1986).

Crosses of amoebal strains. Amoebae to be crossed were cultured on LIA with SBS for a few days so that they were in active growth; they were then inoculated with toothpicks in $0.02 \mathrm{ml}$ 'puddles' of SBS on DSDM agar or DSDM agar + citrate; the amoebae were mixed together in the puddle and incubated without spreading. Crosses were incubated at $26^{\circ} \mathrm{C}$, or at $29^{\circ} \mathrm{C}$ when necessary to inhibit apogamic development of mat $A h$ strains. Each cross was set up on a series of plates and only one plasmodium was harvested from each plate; macroscopic plasmodia were cut out on a block of agar and transferred to SDM agar. Plasmodial fusion-type was checked by fusion tests with appropriate tester strains and spores were obtained only from heterozygous plasmodia that gave unambiguous results in these tests (Dee, 1982).

Culture of plasmodia and sporulation. Plasmodia were cultured on SDM agar at $26^{\circ} \mathrm{C}$ and subcultured at intervals of approximately 1 week. To induce sporulation, plasmodia were incubated on SDM agar in the dark until the medium was exhausted and the protoplasm was concentrated in large veins (1-2 weeks); the plates were then inverted and placed on a Perspex sheet $25 \mathrm{~cm}$ above two $20 \mathrm{~W}$ 'Daylight' fluorescent tubes in a purpose-built box situated in a $22^{\circ} \mathrm{C}$ constant-temperature room. To prevent over-heating of the cultures, the lights were operated through a time-switch which gave alternate $6 \mathrm{~h}$ periods of light and darkness, and a fan which circulated air over the fluorescent tubes was switched-on simultaneously with the lights. Sporangia, which usually formed within a few days, were harvested with a spatula, dried in Petri dishes and stored in screw-cap bottles.

Analysis of crosses. Since earlier attempts to analyse crosses involving CLd-AXE or its derivatives were unsuccessful because a large proportion of the progeny were diploid, aneuploid or of parental genotype (Chainey, 1981 ; J. Dee, unpublished), special measures were adopted to avoid these difficulties (see Dee, 1986). For each cross, several batches of spores obtained from different plasmodia were screened for the presence of aneuploid or diploid progeny by the following procedure. Sporangia were crushed with a dry spatula to break up large clumps and a sample of spores was transferred to $0.3 \mathrm{ml}$ water to make a dense suspension which was allowed to stand for $2-3 \mathrm{~h}$. The suspension was then examined in a haemacytometer, spore morphology and the approximate frequency of hatched spores were recorded, and samples of the suspension were plated on six LIA plates. All plates were initially incubated at $26^{\circ} \mathrm{C}$ but one pair was transferred to $30^{\circ} \mathrm{C}$ after $2 \mathrm{~d}$ and one pair after $3 \mathrm{~d}$. Spore batches that showed plasmodium formation in a high proportion of colonies on the plates transferred to $30^{\circ} \mathrm{C}$ were discarded, since this is an indication of the presence of diploid or aneuploid cells heterozygous for matA (Adler \& Holt, 1975). Spore viability was also estimated by approximate counts of unhatched spores visible on the plates. For each cross, a spore batch was chosen for further analysis which had shown good viability and a high proportion of normal amoebal colonies; a fresh spore suspension, diluted appropriately, was plated on LIA with SBS to give single colonies for progeny analysis. Amoebae obtained from these colonies were re-plated and a set of progeny clones of amoebae was isolated and cultured on bacterial lawns as described above.

Classification of progeny from crosses. To check that there was no excess of the parental type, a sample of progeny clones from each cross was tested for free recombination of known unlinked loci before further analysis was done. Classification for mat loci was by mating tests with an appropriate set of tester strains on DSDM agar or DSDM agar + citrate at $30^{\circ} \mathrm{C}$. Tester strains were used that carried recessive alleles at loci expressed only in plasmodia, so that plasmodia obtained from the tests could be used to classify progeny for these loci. Since mat $A h$ npfC clones have mat $A 2$ mating specificity at $30^{\circ} \mathrm{C}$ (Anderson, 1979) this genotype could also be classified by mating tests. Progeny clones were tested for their ability to form 'selfed' or $n p f C^{+}$revertant plasmodia in puddles of $0.02 \mathrm{ml} \mathrm{SBS}$ on DSDM agar incubated at $26^{\circ} \mathrm{C}$; plasmodia obtained from these tests were used to classify the clones for markers expressed only in plasmodia. Plasmodia were classified for nutritional requirements as described by Dee \& Anderson (1984).

Tests of amoebal progeny clones in liquid, axenic medium. Before tests in liquid medium, amoebae were transferred from cultures with live E. coli to FKB on LIA containing penicillin and streptomycin (see 'Media'). Each clone was normally tested in duplicate and a separate $50 \mathrm{~mm}$ Sterilin Petri dish was used for each test. Plates were poured at least $4 \mathrm{~d}$ before use. A droplet of $0.04 \mathrm{ml} \mathrm{FKB}$ suspension was inoculated on the agar surface and spread to form a 
patch $10-15 \mathrm{~mm}$ in diameter. When the liquid had soaked into the agar, the amoebae were inoculated in the middle of the patch with a toothpick. Incubation was as for cultures on live $E$. coli depending on the genotype of the strain (see above). When the amoebae had grown to form a sufficiently large single patch (1-2 weeks), a block of surface area at least $5 \times 5 \mathrm{~mm}$ and up to $5 \times 15 \mathrm{~mm}$, was cut from the agar underlying the amoebal growth, and transferred to $1 \mathrm{ml} \mathrm{SDM}$ in a test-tube. Care was taken to minimize the amount of FKB included with the block since there was evidence that the presence of FKB in the liquid medium might inhibit amoebal growth. Amoebae were freed from the agar surface by agitation for about $10 \mathrm{~s}$ with a vortex mixer, and a sample of the suspension was counted in a haemacytometer. Both rounded and apparently active, amoeboid cells were usually seen at this stage; cell fragments, which were not counted, were sometimes present also. Using a standardized procedure for the inoculation and sampling of the cultures on FKB, the cell density in the SDM suspension was usually found to be between $5 \times 10^{5}$ and $1 \times 10^{6}$ cells $\mathrm{ml}^{-1}$; if necessary, appropriate adjustments were made so that the cell density would be within this range. This 'initial culture' was then transferred to a culture vessel and incubated as described below. After approximately $7 \mathrm{~d}$, the initial culture was sampled, counted in a haemacytometer, and cell morphology was noted. Strains that failed to show any increase in cell number in the initial culture usually contained cells that were small, rounded and apparently inactive; such cultures were re-incubated without subculturing and the strains could usually be classified unambiguously as non-growers ('non-Axe' phenotype) because they failed to grow in repeated tests. Strains that increased in cell number in the initial cultures were diluted with fresh SDM to give a cell density of $5 \times 10^{5}$ to $1 \times 10^{6}$ cells $\mathrm{ml}^{-1}$ and the diluted suspension ("first subculture') was transferred to a fresh culture tube, incubated, and counted after 5-7 d. For some crosses, a second subculture was also scored. Growth rate in the subcultures was expressed as a doubling time (in hours) which was measured after plotting cell numbers for the inoculum and yield in each subculture. Progeny clones were classified as able to grow in axenic medium ('Axe' phenotype) if their doubling time was less than or equal to $100 \mathrm{~h}$. Clones with a doubling time greater than $100 \mathrm{~h}$ were classified as non-Axe or 'doubtful'.

For one set of experiments (see Results), amoebae were tested in liquid medium by transferring them directly from lawns of $E$. coli on LIA plates to liquid SDM containing penicillin ( 250 units $\left.1^{-1}\right)$ and streptomycin ( 250 units $\left.1^{-1}\right)$. Subcultures were made in the same medium until tests on nutrient agar indicated that live bacteria were no longer present; the antibiotics were then omitted. In all other respects, the method for inoculating the amoebae in liquid medium was as described above.

Culture of amoebae in liquid, axenic media. Culture vessels were $16 \times 100 \mathrm{~mm}$ disposable, conical-base test-tubes supplied sterile with screw-cap in place (Sterilin product no. $144 \mathrm{AS}$ ). Each tube contained 1-2 ml SDM and, except where otherwise specified, the inoculum was at least $2 \times 10^{5}$ cells ml ${ }^{-1}$. Cultures were incubated at $26^{\circ} \mathrm{C}$ except for mat $A h$ or mat $A h n p f C$ strains, which were usually incubated at $30^{\circ} \mathrm{C}$ to inhibit plasmodium formation. Cultures were incubated on reciprocating shakers $\left(200\right.$ strokes $\left.\mathrm{min}^{-1}\right)$ which agitated the medium along the long axis of the tube; the tubes were positioned in clasps which tilted them at an angle of approximately $45^{\circ}$ to the horizontal (see Dee, 1986 for illustration).

Assays for cells committed to plasmodium development. As described previously (Youngman et al., 1977; Burland et al., 1981), suspensions made from cultures in which apogamic plasmodium development is occurring give rise to two types of growth when re-plated on bacterial lawns: amoebal colonies and isolated, migrating plasmodia; the latter arise from cells committed to development at the time of re-plating. A modification of previous methods was used to assay for committed cells in axenic cultures. The cells were suspended and diluted in fresh SDM and $0 \cdot 1 \mathrm{ml}$ samples were plated on DSDM/LIA with $0 \cdot 1 \mathrm{ml} \mathrm{SBS}$ and incubated at $26^{\circ} \mathrm{C}$. Plates were scored after $3 \mathrm{~d}$ and rescored at intervals until $10 \mathrm{~d}$ after plating.

Induction of the amoeba-flagellate transformation. The methods used were based on those of Blindt (1987). To induce flagellate formation in amoebae from bacterial lawns, cultures were washed off LIA plates with water after $3 \mathrm{~d}$ incubation, and suspensions of approximately $10^{7}$ cells $\mathrm{ml}^{-1}$ were incubated for $3 \mathrm{~h}$ at $26^{\circ} \mathrm{C}$ on a reciprocating shaker, as described for liquid, axenic cultures (see above). These suspensions contained some encysted cells which were not expected to form flagellates. Estimates of the proportion of cysts in the suspensions agreed with counts of the proportion of dense rounded cells present after staining (see below) and these cells were excluded when the percentage of flagellates was calculated.

All tests of flagellate formation in amoebae from liquid SDM were done with cultures which had been incubated for 4-6 d and had reached a cell density between $4 \times 10^{6}$ and $1.5 \times 10^{7}$ cells ml ${ }^{-1}$. A sample $(1 \mathrm{ml})$ of culture was diluted with $3 \mathrm{ml}$ distilled water and centrifuged at 1800 r.p.m. for $1 \mathrm{~min}$. After removal of $3 \mathrm{ml}$ of supernatant, the cells were resuspended in the remaining liquid and incubated at $26^{\circ} \mathrm{C}$ for $30 \mathrm{~min}$ on a reciprocating shaker (see above). The suspension was then diluted with $3 \mathrm{ml}$ distilled water, spun down for $1 \mathrm{~min}$ at 1800 r.p.m., the supernatant poured off and the pellet resuspended in $1 \mathrm{ml}$ water. The cell density was checked by haemacytometer counts, and the suspension incubated on the reciprocating shaker (see above) at $26^{\circ} \mathrm{C}$ for $3 \mathrm{~h}$ to induce flagellate formation. In all tests, the estimated cell density during this final period of incubation was greater than $4 \times 10^{6}$ cells $\mathrm{ml}^{-1}$ and in most tests it was near $10^{7}$ cells $\mathrm{ml}^{-1}$; cell density was maintained within this range because Blindt (1987) found a significantly reduced frequency of flagellates in suspensions with density lower than $10^{6} \mathrm{cells}^{-1}$. 
After $3 \mathrm{~h}$, the suspension was removed from the shaker, a small sample was removed to check the appearance of the cells, and the remainder was immediately stained by the addition of two drops of Lugol's Iodine (Wenrick \& Diller, 1950). The frequency of flagellates was estimated by scanning a drop of the stained suspension on a slide with the aid of a phase-contrast $\times 40$ objective. Fields free of large clumps were selected and all cells within an area defined by a squared eyepiece grid were scored as flagellates or non-flagellates. Suspensions of amoebae from liquid axenic medium, unlike those from bacterial lawns, contained only a very small proportion of cells that appeared to be encysted; these were not included when the frequency of flagellates was calculated.

Flow cytometry. Cells were stained with mithramycin and analysed by flow cytometry as described by Bailey $e t$ al. (1987).

\section{RESULTS AND DISCUSSION}

\section{Crosses between $C L d-A X E$ and strains unable to grow in axenic medium}

CLd-AXE amoebae obtained from the McArdle Laboratory (Madison, Wis., USA) were crossed with four heterothallic strains, LU213, LU299, LU862 and RA272 (see Methods and Table 1). Initially, about 25 progeny clones from each cross were tested and some progeny able to grow in axenic medium were found in each cross but in some cases the proportion of this type was small. On the basis of these tests, two crosses, CLd-AXE $\times$ LU213 and CLdAXE $\times$ RA272, were chosen for further analysis. Sixty progeny clones were isolated from each of these crosses but a few were later excluded from the analysis because their hybrid plasmodial fusion type indicated that they were aneuploid or diploid.

Segregation of the Axe phenotype among progeny. All progeny clones were tested for growth in axenic medium several times. In both crosses, many clones failed to grow in the initial culture in all tests and could be classified unambiguously as non-Axe. For clones that grew in the initial culture, doubling time was calculated from initial and final cell counts in the first subculture and the mean was obtained from several tests (Fig. $1 a, b$ ). With the standard inoculum and incubation times used, the doubling times in Fig. 1 can be assumed to be close to those that would be measured during the exponential phase of a growth curve (see Fig. 2). Most clones showed good reproducibility between tests and doubling times less than $70 \mathrm{~h}$ but all clones with mean doubling times of $100 \mathrm{~h}$ or less were classified as Axe. A few clones in each cross showed some apparent growth in the initial culture but had a doubling time of more than $100 \mathrm{~h}$ in the subculture; most of these were classified 'doubtful' because they apparently showed very slow growth; a few were classified non-Axe because they showed no growth in the subculture.

The segregation of Axe to non-Axe clones among the progeny of CLd-AXE $\times$ LU213 (Table 2) was consistent with the $1: 1$ ratio expected if ability to grow in axenic medium were determined by a single gene, and showed a significant deviation from the $1: 3$ ratio expected if two unlinked genes were required for growth, as had been suggested by McCullough et al. (1978). The segregation observed among the progeny of CLd-AXE $\times$ RA272, however, might support either model, depending on how the 'doubtful' clones are classified (Table 2). The justification for including all Axe strains in a single class and possible explanations for 'doubtful' growth are discussed later, in the context of relevant observations arising from other experiments.

Classification of progeny for known genetic markers. Progeny of CLd-AXE $\times$ LU213 were classified for mat $A$, mat $B$, fus $A$ and leuA. All loci showed $1: 1$ segregation of alleles and free recombination as expected. A total of 39 clones could be fully classified for all four markers and for growth in axenic medium and among these, 19 were classified Axe and 20 non-Axe. Progeny of CLd-AXE $\times$ RA272 were classified for $m a t A$, fus $A$ and whiA. All allelic pairs segregated 1:1 and recombined freely as expected. Among 48 clones fully classified for all three markers and for growth in axenic medium, 16 were classified Axe and 32 non-Axe. There was no evidence in either cross for linkage between the genes determining growth in axenic medium and any of the other loci.

\section{Inheritance of abnormal characteristics among progeny of CLd-AXE}

Progeny of both crosses classified as matAh on the basis of mating tests were tested for their ability to give rise to plasmodia in clones on bacterial lawns. The morphology and sporulation of 
Doubling time $(\mathrm{h})$

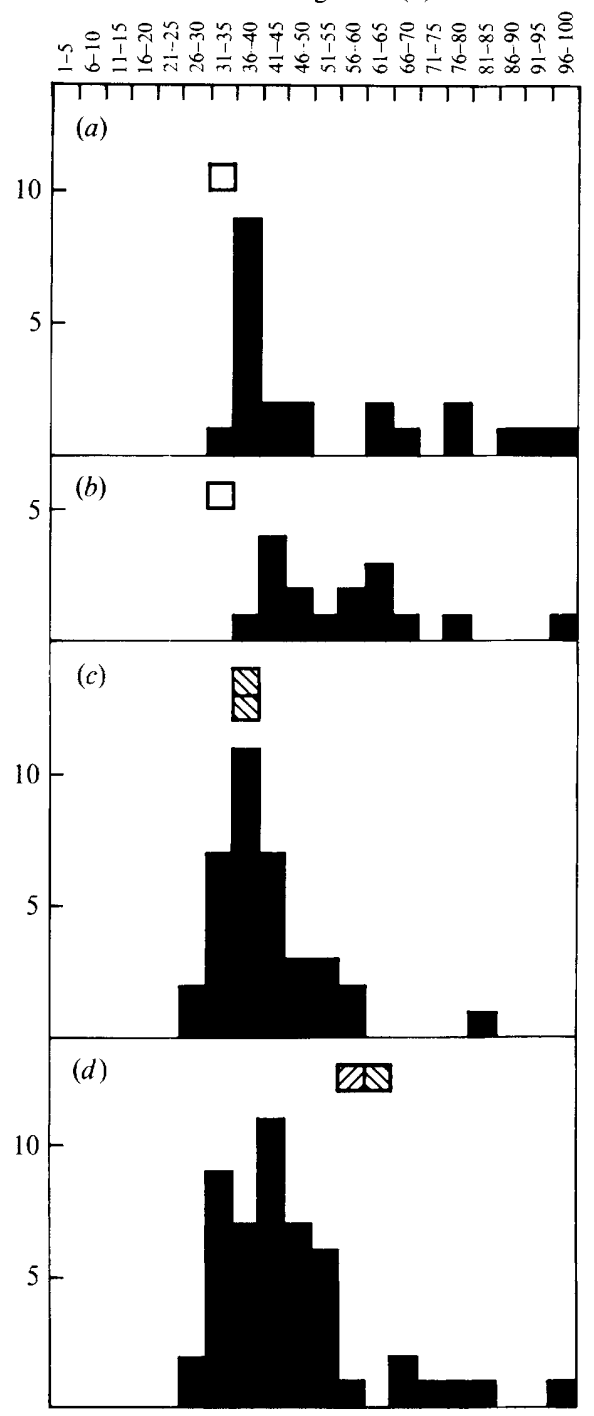

Fig. 1. Growth in liquid axenic medium of Axe progeny clones from crosses. Doubling times were calculated for $(a)$ and $(b)$ from counts on the first subculture and for $(c)$ and $(d)$ from counts on the first and second subcultures. Initial and final $(6$ or $7 \mathrm{~d})$ counts were made on each subculture. A single mean figure, based on several tests, is given for each progeny clone ( $\boldsymbol{\square})$. Mean doubling times for parent strains are also shown. (a) CLd-AXE ( $\square) \times$ LU213 (non-Axe); (b) CLd-AXE ( $\square$ ) $\times$ RA272 (non-Axe);

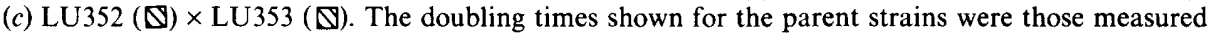
when they were originally classified with other progeny clones from cross $(a)$. (d) LU359 ( $\mathbb{\text { L }}) \times$ LU381 (D). The doubling times shown for the parent strains were those measured when they were originally classified; LU359 was a progeny clone from cross (a), LU381 from cross (b).

the selfed plasmodia were also examined. In both crosses, approximately half the matAh progeny clones resembled their parent, CLd-AXE, in giving rise to selfed plasmodia very rarely or not at all: 10/23 in CLd-AXE $\times$ LU213 and 13/26 in CLd-AXE $\times$ RA272 were of this type. The remainder of the progeny resembled CLd in selfing ability, indicating that their genotype was probably mat $A h n p f C$. These results suggested that, in addition to $n p f C$, a further mutation blocking apogamic plasmodium formation was present in CLd-AXE, in a locus unlinked to $m a t A$ and $n p f C$. Evidence for such a mutation had previously been obtained by Chainey (1981). 


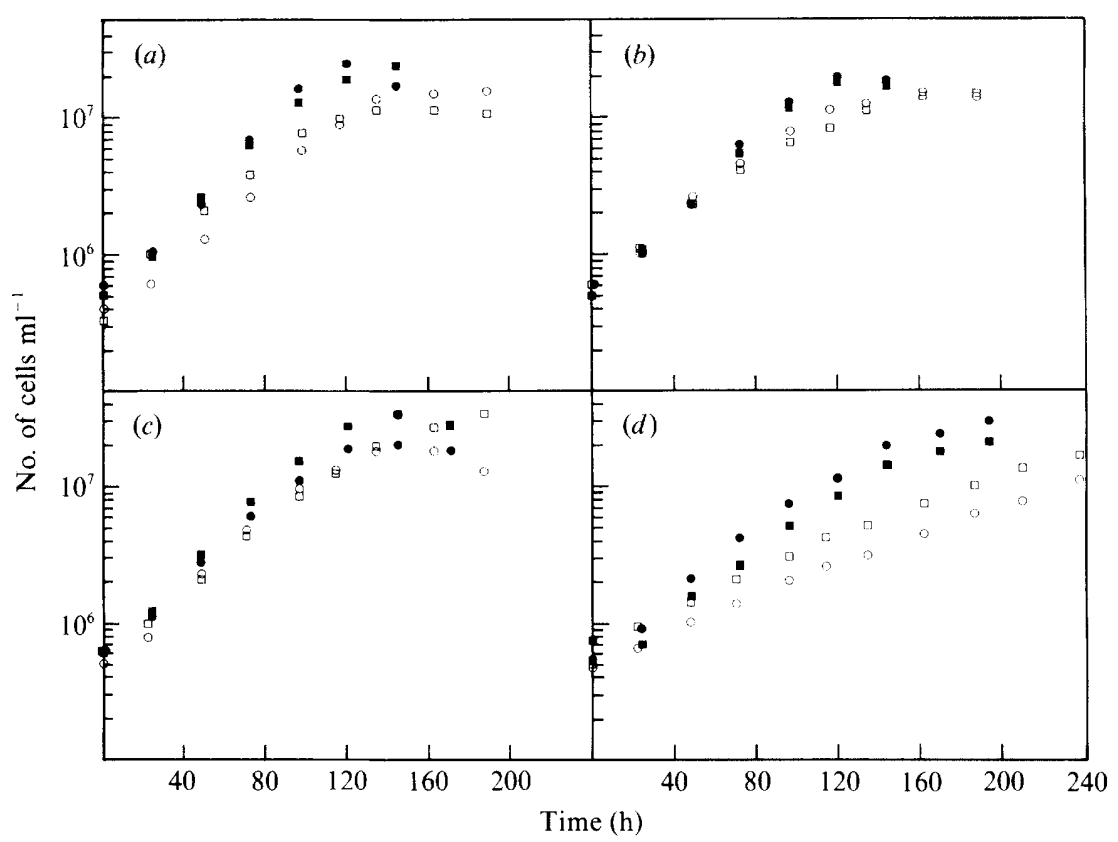

Fig. 2. Growth curves for selected Axe amoebal strains in liquid axenic medium measured at early and late stages during a prolonged series of subcultures. Cell density was calculated from haemacytometer counts; each point is the mean for two tubes of the same subline $[O, O$, subline (i); $\square, \square$, subline (ii)]. The cultures used for these growth curves were set up from the same cell suspensions and at the same time as the routine subcultures specified below. The doubling time (mean value for the two sublines) estimated from the exponential growth phase in each experiment is shown in parentheses (compare with Table 3). (a) LU352 $\left(30^{\circ} \mathrm{C}\right): \mathrm{O}, \square, 8$ th subculture $(24 \mathrm{~h}) ; 0, \square, 26$ th subculture $(18 \mathrm{~h})$. (b) LU600 $\left(30^{\circ} \mathrm{C}\right): \bigcirc, \square, 8$ th subculture $(24 \mathrm{~h}) ; \bigcirc, \square, 26$ th subculture $(20 \mathrm{~h})$. (c) LU353 $\left(26^{\circ} \mathrm{C}\right): \bigcirc, \square, 5$ th subculture $(22 \mathrm{~h}) ; 0,23 \mathrm{rd}$ subculture $(18 \mathrm{~h}) .(d)$ LU381 $\left(26^{\circ} \mathrm{C}\right): \mathrm{O}, \square, 3$ rd subculture $(44 \mathrm{~h}) ; \bigcirc, \square$, 21 st subculture $(28 \mathrm{~h})$.

Table 2. Classification of progeny clones from Axe $\times$ non-Axe crosses for ability to grow in liquid axenic medium

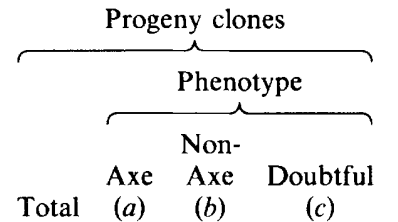

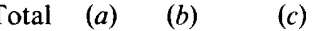

$\begin{array}{lccccl}\text { CLd-AXE } \times \text { LU213 } & 53 & 22 & 28 & 3 & \begin{array}{l}a: b \\ a:(b+c) \\ (a+c): b\end{array} \\ \text { CLd-AXE } \times \text { RA272 } & 55 & 16 & 32 & 7 & \begin{array}{l}a: b \\ a:(b+c) \\ (a+c): b\end{array} \\ \text { LU352 } \times \text { LU481 } & 89 & 21 & 62 & 6 & \begin{array}{l}a: b \\ a:(b+c) \\ (a+c): b \\ a: b\end{array} \\ \text { LU381 } \times \text { CLd } & 46 & 13 & 33 & 0 & \end{array}$

Tests for agreement with genetic models*

\begin{tabular}{|c|c|c|}
\hline & $\begin{array}{l}\text { One axe gene } \\
\text { Axe. }\end{array}$ & $\begin{array}{l}\text { Two axe genes } \\
\text { Axe } 3 \text {-Axe }\end{array}$ \\
\hline tested & $\chi^{2}$ & $\chi^{2}$ \\
\hline
\end{tabular}

* The two-gene model tested assumes that both mutations are required for growth in axenic medium. A value below 3.84 indicates that the observed segregation does not deviate significantly from the expected ratio.

+ Significant deviation at the $5 \%$ level.

$\ddagger$ Significant deviation at the $1 \%$ level. 
This had presumably arisen at some time after CLd-AXE was derived from CLd, since the selfing ability of CLd-AXE was originally as expected for a mat Ah $n p f C$ strain (McCullough $e t$ al., 1978). There was no evidence that this mutation was linked to any of the marker genes in either cross.

Some of the selfed plasmodia obtained from mat $A$ h progeny showed abnormal morphology and several different characteristic phenotypes were observed among these strains. Test crosses of some progeny clones with one another and with CLd-AXE indicated that the abnormalities did not have a simple genetic basis and there was no evidence that they were due to mutations carried by CLd-AXE. Not surprisingly, most of the abnormal plasmodia failed to sporulate. In addition about half of the selfed plasmodia with normal morphology also failed to give any normal sporangia although tested repeatedly: 6/12 clones from CLd-AXE $\times$ LU213 and 3/8 clones from CLd-AXE $\times$ RA272 were of this type. These results suggested that a mutation affecting sporulation, possibly derived from CLd-AXE, might be segregating in both crosses. Poor sporulation observed in some hybrid plasmodia produced by crossing progeny clones with one another or with CLd-AXE supported this conclusion.

In both crosses, the ability to grow in axenic medium reassorted with the abnormalities of selfing, plasmodium morphology and sporulation, and there was no clear evidence of linkage between any of the genes responsible for these characteristics. Thus it was possible to find progeny clones that grew well in axenic medium and were free of all these abnormalities. It was concluded that, although CLd-AXE had probably accumulated some mutations during its history, there was no reason to suppose that these were associated in any way with the genes determining growth in axenic medium.

\section{Axe strains selected for further analysis}

From the progeny of CLd-AXE $\times$ LU213 and CLd-AXE $\times$ RA272, several Axe strains were selected for further analysis because they were potentially suitable for particular types of research work. Strain LU352 (Table 1) had the genotype mat $A h n p f C$ and readily produced revertant $\left(n p f C^{+}\right)$plasmodia when cultured on bacterial lawns; these plasmodia were morphologically normal and sporulated well. LU352 amoebae repeatably grew well in axenic medium and plasmodium formation in these cultures could be avoided by incubation at $30^{\circ} \mathrm{C}$. Clones of amoebae obtained from spores produced by LU352 revertant plasmodia also grew well in axenic medium and, when plated on bacterial lawns, at temperatures below $30^{\circ} \mathrm{C}$, these amoebae formed selfed plasmodia in single colonies as expected: one such clone, designated LU600 (Table 1), was selected for further analysis together with LU352. These two strains were potentially suitable for mutant isolation and studies of gene expression and apogamic development and might in future be used in place of CL and CLd respectively.

Strain LU381 (Table 1) was the only Axe clone so far identified with the genotype required for efficient crosses with CL and CLd. Such a strain was necessary because an interesting range of mutants had already been isolated in CLd, for example, the BEN mutants resistant to microtubule inhibitors (Burland et al., 1984). An Axe derivative strain of one of these mutants had been made, but this had required a series of crosses and genetic analysis (T. G. Burland, personal communication). The Axe strain allowed studies on the tubulin isotype that is the benD gene product and demonstrated that the ben mutation had caused altered function in vitro (Foster et al., 1987). For further studies of this kind, it was necessary to facilitate Axe strain construction, and LU381 was chosen for this purpose. Two other heterothallic Axe strains, LU353 and LU359, were also selected for further analysis because their genotypes were suitable for crossing with LU352 and LU381 (Table 1).

Before selecting the heterothallic strains, attempts were made, by means of test crosses with abnormal mat $A h$ strains, to investigate whether they carried any of the mutations affecting plasmodium morphology or sporulation that were apparently segregating among the progeny of CLd-AXE $\times$ LU213 and CLd-AXE $\times$ RA272. Since the possible test crosses were severely limited by the genotypes of the strains, and the results suggested that these abnormalities did not have a simple genetic basis, it was concluded that it would not be possible to identify heterothallic strains that were free of these undesirable mutations without a much more lengthy 
analysis. There were of course no such difficulties with the matAh strains LU352 and LU600 since selfed plasmodia had been obtained and were found to be normal.

\section{Analysis of crosses involving the selected Axe strains}

LU352 $\times$ LU353 and LU359 $\times$ LU381. Thirty-seven progeny clones from LU352 $\times$ LU353 and 52 progeny from LU $359 \times$ LU381 were tested for growth in liquid axenic medium: only one clone from the first cross and three from the second failed to grow. In these crosses, doubling times were calculated from counts on the first and second subcultures (See Fig. 1c,d) unlike the earlier crosses in which only the first subculture was used (Fig. $1 a, b$ ). The shorter doubling times observed may have been partly due to this change in procedure, since it was found that growth rate usually improved during the first few subcultures. The parent strains were also tested several times: LU352 and LU353 repeatedly showed doubling times between 35 and $45 \mathrm{~h}$; LU359 varied between 35 and $65 \mathrm{~h}$ in different tests, and LU381 varied between 37.5 and $80 \mathrm{~h}$. Thus, although the four parent strains differed in their mean doubling times, their best doubling times were very similar and close to the peaks of the distributions shown by the progeny. The variable results for the parent strains and the very similar distributions found for the two sets of progeny indicated that all the strains in these crosses may be regarded as sharing the same Axe phenotype and suggested that they may all carry the same major axe genes.

Samples of progeny from both crosses were tested for the other genetic markers present in the parents. All the marker genes showed the expected segregation ratios and recombination frequencies, confirming that the progeny samples were haploid products of meiosis in heterozygous nuclei. The genetic analysis of these two crosses indicated that the selected strains could be used to generate a range of new Axe strains sharing the ability to grow well in axenic medium but carrying a wide range of known genetic markers.

$L U 352 \times L U 481$ and $L U 381 \times C L d$. In these two crosses, between Axe strains and strains unable to grow in axenic medium, progeny were classified as Axe, non-Axe or 'doubtful' by the criteria used in the CLd-AXE crosses. In both crosses, less than half of the progeny showed the Axe phenotype (Table 2); the observed segregation was consistent with the two-gene model proposed by McCullough et al. (1978) and disagreed significantly with the expectation based on a single axe gene. Among the Axe progeny, the range of doubling times was similar to that found in previous crosses. The expected segregation and recombination of other genetic markers were found in samples of progeny from both crosses, indicating that these were the normal haploid products of meiosis in heterozygous nuclei. Recombination was also observed between the Axe phenotype and known genetic markers, including $l y s B$, which had not been present in previous crosses. The results indicated that both LU352 and LU381 could be used effectively for Axe strain construction, and that LU381 was a suitable strain for making Axe derivatives of mutants isolated in CLd.

\section{Growth of selected Axe strains during prolonged culture in liquid axenic medium}

To investigate whether the selected Axe strains remained stable and suitable for analysis during prolonged culture in liquid axenic medium, they were maintained in active growth for a period of about 4 months. The cellular DNA content and other properties were tested repeatedly during this time, as described in later sections. These long-term cultures were initiated from cloned stock cultures which had been stored on bacterial lawns at $4{ }^{\circ} \mathrm{C}$ while the genetic analysis of the CLd-AXE crosses was done. The four selected strains (LU352, LU600, LU353 and LU381) and the parent strain CLd-AXE were re-inoculated into liquid medium and two sublines of each strain were set-up at the first subculture. The two sublines were maintained separately for approximately 20 successive subcultures. LU352 and LU600 were incubated at $30^{\circ} \mathrm{C}$ to inhibit plasmodium formation; the other strains were incubated at $26^{\circ} \mathrm{C}$. On two occasions, at an early and late stage in the subculturing series, growth curves were constructed for all strains on the basis of daily counts over a period of up to $10 \mathrm{~d}$ (Fig. 2). All the strains showed a slightly increased growth rate and yield in the second experiment. The growth curves showed that the amoebae grew exponentially for at least $5 \mathrm{~d}$ after inoculation when an inoculum of 
Table 3. Growth of selected Axe strains during a prolonged series of subcultures in liquid axenic medium

Doubling times were calculated from initial and final haemacytometer counts for each subculture (final count after $5 \mathrm{~d}$ except where stated otherwise). Two sublines (i and ii) were maintained for each strain. In the first subculture, the value given is for the single tube used to initiate each subline; for all other subcultures, doubling time was calculated from mean counts on two or three tubes.

\begin{tabular}{|c|c|c|c|c|c|c|c|c|c|c|}
\hline \multirow[b]{3}{*}{ Subculture } & \multicolumn{10}{|c|}{ Doubling time $(\mathrm{h})$} \\
\hline & \multicolumn{2}{|c|}{$\begin{array}{l}\text { LU352 } \\
\left(30^{\circ} \mathrm{C}\right)\end{array}$} & \multicolumn{2}{|c|}{$\begin{array}{l}\text { LU600 } \\
\left(30^{\circ} \mathrm{C}\right)\end{array}$} & \multicolumn{2}{|c|}{$\begin{array}{l}\text { LU353 } \\
\left(26^{\circ} \mathrm{C}\right)\end{array}$} & \multicolumn{2}{|c|}{$\begin{array}{l}\text { LU381 } \\
\left(26^{\circ} \mathrm{C}\right)\end{array}$} & \multicolumn{2}{|c|}{$\begin{array}{c}\text { CLd-AXE } \\
\left(26^{\circ} \mathrm{C}\right)\end{array}$} \\
\hline & (i) & (ii) & (i) & (ii) & (i) & (ii) & (i) & (ii) & (i) & (ii) \\
\hline 1 & $55 \cdot 0$ & $52 \cdot 5$ & $32 \cdot 5$ & $30 \cdot 0$ & $32 \cdot 5$ & $27 \cdot 5$ & $97 \cdot 5^{*}$ & $80 \cdot 0^{*}$ & $27 \cdot 5$ & 30.0 \\
\hline 2 & $40 \cdot 0$ & $37 \cdot 5$ & $37 \cdot 5$ & $40 \cdot 0$ & $22 \cdot 5$ & $25 \cdot 0$ & $50 \cdot 0 \dagger$ & $52 \cdot 5 \dagger$ & $25 \cdot 0$ & $25 \cdot 0$ \\
\hline 3 & $35 \cdot 0$ & $32 \cdot 5$ & $27 \cdot 5$ & $32 \cdot 5$ & $20 \cdot 0$ & $22 \cdot 5$ & $55 \cdot 0$ & $40 \cdot 0$ & $20 \cdot 0$ & $20 \cdot 0$ \\
\hline 4 & $27 \cdot 5$ & $27 \cdot 5$ & $30 \cdot 0$ & $30 \cdot 0$ & $20 \cdot 0$ & $25 \cdot 0$ & $40 \cdot 0$ & $40 \cdot 0$ & $22 \cdot 5$ & $20 \cdot 0$ \\
\hline 5 & $32 \cdot 5$ & $32 \cdot 5$ & $27 \cdot 5$ & $42 \cdot 5$ & $22 \cdot 5$ & $27 \cdot 5$ & $45 \cdot 0$ & $52 \cdot 5$ & $20 \cdot 0$ & 22.5 \\
\hline 8 & $30 \cdot 0$ & $20 \cdot 0$ & 27.5 & $30 \cdot 0$ & $25 \cdot 0$ & $27 \cdot 5$ & $42 \cdot 5$ & $40 \cdot 0$ & $22 \cdot 5$ & 22.5 \\
\hline 11 & $25 \cdot 0$ & $37 \cdot 5$ & $25 \cdot 0$ & $35 \cdot 0$ & $22 \cdot 5$ & $25 \cdot 0$ & $40 \cdot 0$ & $55 \cdot 0$ & $27 \cdot 5$ & $25 \cdot 0$ \\
\hline 14 & $25 \cdot 0$ & $25 \cdot 0$ & $27 \cdot 5$ & $27 \cdot 5$ & $25 \cdot 0$ & $25 \cdot 0$ & $30 \cdot 0$ & $35 \cdot 0$ & $25 \cdot 0$ & $25 \cdot 0$ \\
\hline 19 & $22 \cdot 5$ & $22 \cdot 5$ & $30 \cdot 0$ & $30 \cdot 0$ & $22 \cdot 5$ & $22 \cdot 5$ & $35 \cdot 0$ & $35 \cdot 0$ & $22 \cdot 5$ & 25.0 \\
\hline 23 & $25 \cdot 0$ & 25.0 & 27.5 & $27 \cdot 5$ & $27 \cdot 5$ & $20 \cdot 0$ & $35 \cdot 0$ & $30 \cdot 0$ & - & - \\
\hline 28 & $25 \cdot 0$ & 30.0 & 27.5 & $27 \cdot 5$ & 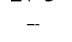 & - & - & - & - & - \\
\hline & & & & $\begin{array}{l}-, \mathrm{No} \\
{ }^{*} \mathrm{Cou} \\
\dagger \mathrm{Cou}\end{array}$ & $\begin{array}{l}\text { o. } \\
\text { on day } \\
\text { on day }\end{array}$ & & & & & \\
\hline
\end{tabular}

approximately $5 \times 10^{5}$ cells $\mathrm{ml}^{-1}$ was used; most strains then reached a plateau with a cell density of about $2 \times 10^{7}$ cells $\mathrm{ml}^{-1}$ and the cells began to form clumps as the plateau was reached; eventually the cell density appears to decline because massive clumps are formed in which the cells cannot be counted.

These growth curves showed that with the inoculum used, subculturing every $5 \mathrm{~d}$ should maintain the cells in active growth, and this regime was therefore adopted during the 4 month period. At each subculture, the cell density was estimated before and after dilution of the 5-dculture; doubling times were then calculated from these counts; a sample of these is shown in Table 3. Because the final count on each subculture was made no later than $5 \mathrm{~d}$ when the cells were still in active growth, the doubling times shown in Table 3 are close to doubling times calculated from the exponential portion of the growth curves (see Fig. 2 legend); it is clear from the growth curves, however, that doubling times based only on a final count after a long culture period would be much less accurate, particularly for fast-growing strains. This factor, together with the increase in growth rate which all strains showed in the first few subcultures, accounts for the longer doubling times shown for the selected strains when they were originally tested (see Fig. 1).

The doubling times shown in Table 3 indicate that all strains increased in growth rate during the first two subcultures and that most strains then showed little further change during the prolonged culture period. LU381 apparently grew extremely slowly at first, showed a big increase in growth rate after three subcultures and a further small increase between the 11 th and 14 th subcultures. LU381 had also shown variable growth in repeated growth tests during the genetic analysis, as described in previous sections. Measurements of DNA content (described in a later section of this paper) revealed a possible basis for the changes in growth rate observed in LU381.

\section{Liquid cultures of LU352 and LU353 grown from low cell densities}

Previous work with liquid axenic cultures of $P$. polycephalum amoebae had suggested that the initial cell density should be at least $5 \times 10^{5}$ cells ml $^{-1}$ to obtain successful growth (McCullough \& Dee, 1976: McCullough et al., 1978) and this inoculum size was used in most of the work 

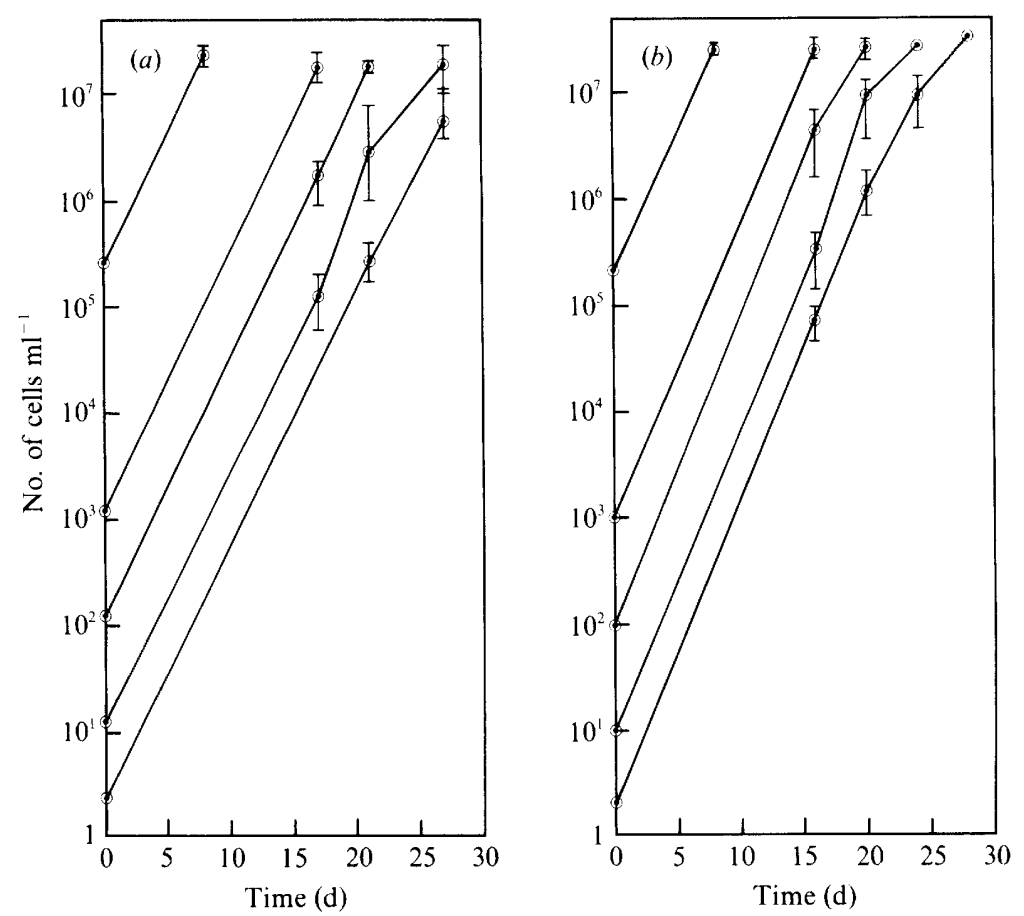

Fig. 3. Growth of Axe amoebae in liquid axenic medium from different initial cell densities. (a) LU352 $\left(26^{\circ} \mathrm{C}\right) ;(b) \mathrm{LU} 353\left(26^{\circ} \mathrm{C}\right)$. Cell densities were estimated directly from haemacytometer counts except for those below $10^{4}$ cells $\mathrm{ml}^{-1}$ which were calculated from a dilution series made from a dense cell suspension at time zero. Values indicated are the mean and range for two to four tubes inoculated with the same cell suspension.

described in this paper. Growth from a smaller number of cells was desirable for certain experimental procedures, however: for example, the isolation of mutants or genetic transformants in axenic conditions. To investigate whether this would be possible, amoebae obtained from established cultures of LU352 and LU353 were inoculated in axenic liquid medium at low cell densities. After a sufficiently long incubation, direct cell counts could be made on all the cultures except some of those where the estimated inoculum had been near zero. The results of two such experiments (Fig. 3) showed that cultures with a wide range of initial inocula grew at very similar rates and eventually reached cell densities between 2 and $3 \times 10^{7}$ cells $\mathrm{ml}^{-1}$. A number of other experiments with the same strains gave very similar results at $26{ }^{\circ} \mathrm{C}$, but attempts to establish cultures from low inocula at $30^{\circ} \mathrm{C}$ were unsuccessful. The doubling times estimated from the growth curves (Fig. 3) were approximately $30 \mathrm{~h}$ for LU352 and $24 \mathrm{~h}$ for LU353, close to those observed in routine cultures inoculated with higher cell densities (Table 3). In all cultures, the cells tended to become rounded and to form clumps when they reached a density greater than $10^{7}$ cells $\mathrm{ml}^{-1}$ but growth apparently continued steadily until this time which was in some cases not reached until several weeks after inoculation. These experiments showed that liquid cultures can be established from very small numbers of cells and that single amoebae can probably be cloned in liquid axenic medium if necessary. It should be noted, however, that no attempts were made to produce liquid cultures from small numbers of amoebae inoculated directly from bacterial lawns.

\section{DNA content of selected Axe strains during prolonged culture}

On the basis of previous reports on CLd-AXE (see Dee, 1986), it was expected that the DNA content of Axe amoebae would increase during prolonged liquid culture and that diploid amoebae might eventually predominate. The DNA contents of amoebae of LU352, LU600, LU353, LU381 and CLd-AXE were measured at intervals during the period of prolonged 
(a)

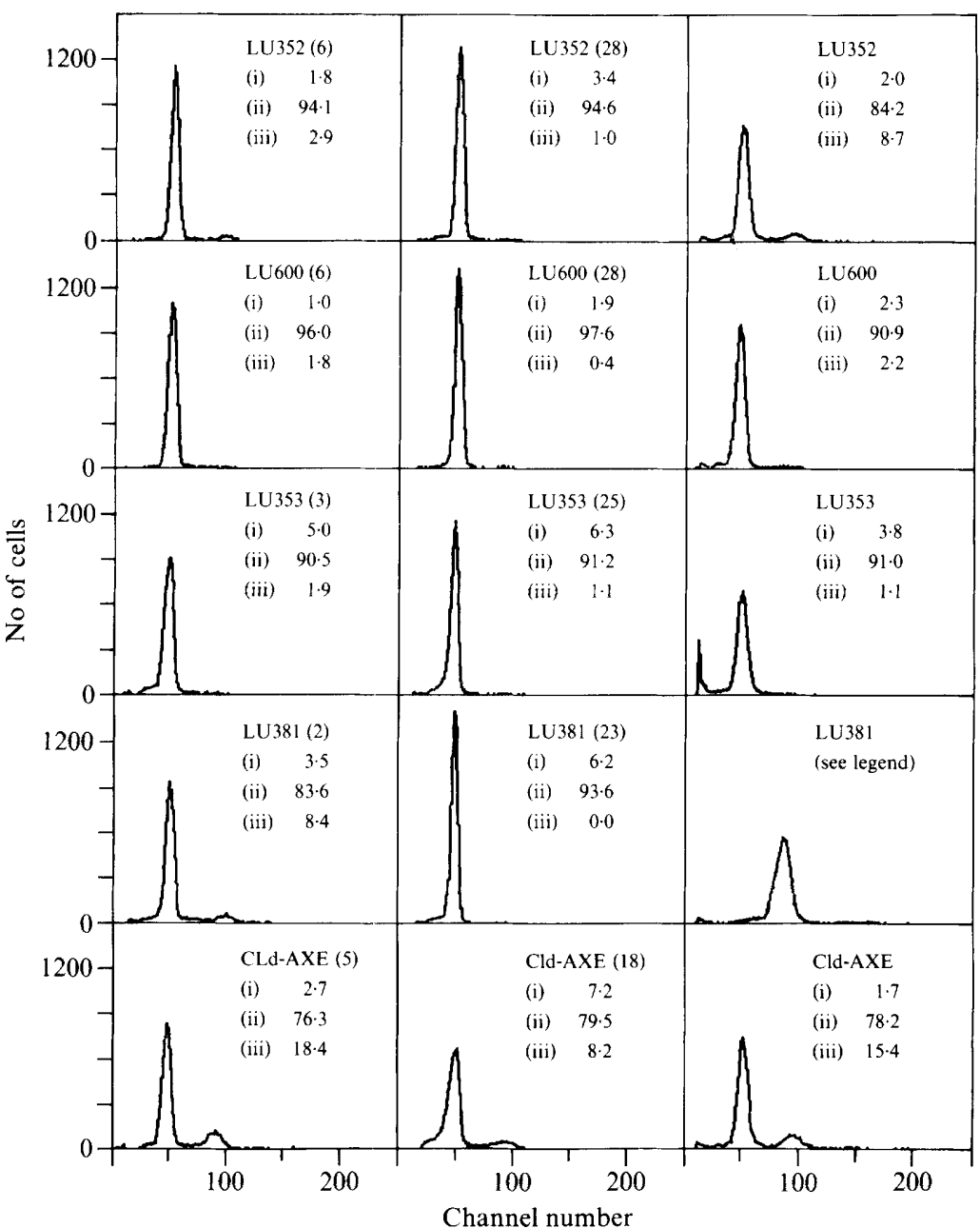

Fig. 4. DNA content of Axe strains measured by flow cytometry of amoebal suspensions stained with mithramycin. Cultures of all five strains were measured at $(a)$ an early stage and $(b)$ a late stage during a prolonged series of subcultures in liquid axenic medium; the subculture number is shown in parentheses after the strain name. Column (c) shows results for the same strains taken from cultures on bacterial lawns. On each panel the percentage of cells (i) in the shoulder to left of main peak, (ii) in the main peak with the mode at or near channel 50 , and (iii) in the secondary peak with the mode at or near channel 100 are indicated. For LU381 on bacteria, $89.6 \%$ of cells were in the main peak with the mode in channel $85,4.6 \%$ in the shoulder, and $2.7 \%$ in a secondary peak with the mode in channel 160 . Channel numbers are directly proportional to DNA content.

culture in liquid axenic medium by means of flow cytometry after staining the cells with the DNA-specific fluorochrome mithramycin. Cultures in exponential growth were used, between 2 and $5 \mathrm{~d}$ after inoculation. The first measurement for each strain was made on an early subculture and subsequent measurements were made at intervals of approximately 1 month. Both sublines of each strain were measured in each test; selected results for individual sublines are shown in Fig. 4. By using a haploid strain of amoebae cultured on bacteria as a control, the flow cytometer was adjusted so that a haploid G2 DNA content would register in or near channel 50 (Bailey $e t$ al., 1987).

In the first test, all strains showed a single main peak with a mode in or near channel 50 and a small second peak with a mode close to channel 100 indicating that a small proportion of cells had approximately twice the haploid DNA content (Fig. $4 a$ ). Contrary to expectation, the 
number of cells in the second peak decreased during prolonged culture of both sublines of all strains, including CLd-AXE. In CLd-AXE, the fastest observed change in the 'diploid' peak was from $18.4 \%$ to $9.4 \%$ between the 5 th and 10 th subcultures of one subline; a smaller decrease occurred between the 10th and 18th subculture (Fig. $4 b$ ). In the four new Axe strains, after about 25 subcultures, only about $1 \%$ or less of the cells were in the region of the second peak (Fig. $4 b$ ).

A shoulder to the left of the main peak shown in Fig. 4 was detected in all tests, usually containing between $1 \%$ and $7 \%$ of the total cells, and these are assumed to be in G1 or S. These results agree with previous evidence that G2 phase makes up the bulk of the amoebal cell cycle and that the combined length of G1 and S is relatively short (Turner et al., 1981; Fry \& Matthews, 1987): it seems likely that $P$. polycephalum amoebae resemble plasmodia in having no G1 period during growth. As shown in Fig. $4(a, b)$ the proportion of cells in the shoulder increased slightly in the later tests, agreeing with the observed increase in growth rates in all strains (see Table 3 and Fig. 2). An observed $6 \%$ of cells in the shoulder, as for LU353 in Fig. $4(b)$, for example, would suggest an S period occupying at least $1.5 \mathrm{~h}$ of the $25 \mathrm{~h}$ doubling time (Table 3). This would be similar to the length of the $\mathrm{S}$ period in a plasmodium growing with an inter-mitotic time of 8-10 h (Braun et al., 1965).

The DNA content of amoebae cultured on bacterial lawns was also measured for all five strains (Fig. 4c). The cell suspensions made from these cultures showed large amounts of bacterial and cell debris in the lowest fluorescence channels but this material was mostly excluded from the traces shown in Fig. 4 by setting a threshold value for the detection of fluorescence. Unlike the liquid cultures, the amoebae from bacterial lawns were mainly encysted cells, but for four of the five strains, the results were similar to those obtained on liquid cultures, indicating that these cells were in G2 phase and disagreeing with the conclusion of Mohberg \& Rusch (1971) that cysts are in G1 phase. Our results are more consistent with those of Fry \& Matthews (1987) who presented evidence that CLd amoebae, cultured on bacteria, form cysts with G2 DNA content after undergoing a pre-encystment G1 phase followed by an S phase.

The LU381 cultures on bacteria unexpectedly showed a main peak with a mode in channel 85 , corresponding to a nearly diploid DNA content, and containing nearly $90 \%$ of the cells. The tests were repeated and the same result was obtained on two further occasions. The origin of these amoebae is obscure, but since LU381 clearly behaved as a haploid strain during the genetic analysis reported in earlier sections, it is assumed that a diploid or aneuploid subline arose during subculturing or storage on bacterial lawns. Since the abnormal subline on bacteria was closely related to the cultures of LU381 used to initiate the liquid cultures, it seems likely that at least some amoebae of abnormal DNA content were inoculated in the liquid medium; this may account for the very slow growth initially observed (Table 3 ). By the second subculture in liquid medium, the LU381 amoebae were predominantly haploid (Fig. $4 a$ ) with only $8.4 \%$ diploids in one subline and $2.7 \%$ in the other; the growth rate had also improved considerably by this time (Table 3). By the 23 rd subculture of LU381, both sublines contained less than $2 \%$ diploid cells. These results suggest that, contrary to the initial expectation, selection may have acted against amoebae of increased DNA content in liquid axenic cultures. An increase in the proportion of haploid nuclei during subcultures of $P$. polycephalum plasmodia containing mixtures of nuclei of different DNA contents has also been observed repeatedly (Mohberg et al., 1973; Turner et al., 1981; Dee \& Anderson, 1984).

\section{Re-plating amoebae from liquid cultures onto bacterial lawns}

Since growth from single cells in liquid axenic medium is very slow, it will be useful if cells can be cloned by re-plating on bacteria after procedures such as mutagenesis, mutant enrichment or DNA transformation have been done in axenic conditions. McCullough et al. (1978) found that CLd-AXE showed low plating efficiency and slow growth when re-plated from liquid axenic medium on bacterial lawns but that an Axe progeny clone from a cross did not show these disadvantages. It was therefore hoped that at least some of the selected Axe strains would grow well when re-plated. To investigate this, amoebae of LU352, LU600, LU353, LU381 and CLdAXE were re-plated on bacterial lawns at intervals during the prolonged period of culture, and a method that gave high plating efficiency was developed. All platings were done with dilutions of 
5-d-old cultures when they were at a high cell density just before routine subculturing; no tests were done with cells from younger cultures. To avoid osmotic shock and possible damage to the cells, dilutions were made in fresh growth medium and vortexing was kept to a minimum; there was evidence that these were important factors affecting cell survival. The dilutions were plated in triplicate on LIA with live E. coli as described in Methods. Plating efficiency was calculated from mean counts on plates containing 30-80 colonies. All five strains, re-plated at an early stage in the period of subculturing, and again after eight more subcultures, showed plating efficiencies of $60 \%$ or higher. In a final test, when all strains had been through about 20 subcultures in liquid medium, LU600 and LU381 showed slightly decreased plating efficiencies of about $50 \%$, but the other strains were unchanged. The changes may not be significant since estimation of plating efficiency is subject to many sources of error. There seems to be no reason to expect difficulties in re-cloning amoebae from axenic liquid cultures by plating them on bacteria, provided that the conditions are carefully controlled. Experiments did suggest, however, that cells from liquid medium are more permeable and fragile than those from bacterial lawns and this should be borne in mind when developing methods for handling them.

During the plating tests, the morphology and mean size of colonies were also recorded and the results indicated that growth was initially very slow on bacterial lawns. After $6 \mathrm{~d}$ incubation, when colonies of about $4 \mathrm{~mm}$ diameter would normally be expected, the average diameter for CLd-AXE colonies was 1-2 $\mathrm{mm}$ and for the other Axe strains 2-3 mm. With longer incubation times, however, large colonies were obtained. Colony morphology was variable, and there were some differences between strains; most colonies formed by LU353 amoebae were diffuse and 'fuzzy', unlike the clearly defined colonies formed by the majority of amoebae in the other four strains.

When serially subcultured on bacterial lawns, Axe strains apparently grew at normal rates; so the very slow growth on re-plating from liquid cultures may be due to the sudden change in conditions of growth rather than the genotype of the Axe strains. A sample of progeny from the cross CLd-AXE $\times$ LU213 was used to investigate whether there was any correlation between the Axe phenotype and growth characteristics on bacterial lawns. In this experiment, the amoebae were re-plated on bacteria within a few hours of being inoculated from bacteria into liquid axenic medium. For 10 Axe clones tested, plating efficiencies were all over $85 \%$, whereas four non-Axe clones gave values between $50 \%$ and $85 \%$. Colony morphology varied among the progeny of this cross, some clones (e.g. LU353) giving very 'fuzzy' colonies, some having clearly defined colonies and many being intermediate in form; but all these types were found among both Axe and non-Axe progeny clones. There was possibly some evidence that the Axe strains grew more slowly on bacterial lawns; the mean colony diameter at $6 \mathrm{~d}$ was $2-3 \mathrm{~mm}$ for most of them, in contrast to $4 \mathrm{~mm}$ for the non-Axe strains. No clear correlation was found, however, between the ability to grow in liquid axenic medium and the number, size or morphology of colonies formed when the amoebae were cultured on bacterial lawns.

When amoebae of the apogamic strain LU600 were re-plated from liquid cultures onto bacterial lawns, incubated at $26^{\circ} \mathrm{C}$, plasmodia were formed in a high proportion of colonies as expected. The frequency of colonies forming plasmodia changed very little during prolonged subculturing. After 25 subcultures in liquid axenic medium, approximately $70 \%$ of colonies of both sublines of LU600 gave rise to macroscopic plasmodia after 6 or $7 \mathrm{~d}$ incubation, by which time the colonies were 3-4 mm in diameter. Amoebae from liquid cultures of LU352 also formed plasmodia on bacterial lawns, but at a much lower frequency, as expected for a mat $A h n p f C$ strain.

\section{Amoebal-plasmodial transition in axenic conditions}

The re-plating experiments described above showed that the ability of LU600 amoebae to develop apogamically into plasmodia was transmitted through many cell generations in liquid axenic medium. The liquid cultures of LU600 and LU352 were normally incubated at $30^{\circ} \mathrm{C}$ in order to prevent apogamic development; even when the cultures were incubated at $26^{\circ} \mathrm{C}$, however, plasmodia were formed only occasionally, and a number of experiments designed to increase the frequency of plasmodium formation in liquid axenic medium were unsuccessful. 
Better results were achieved when the cells were deposited in axenic conditions on a surface. In several experiments, LU600 amoebae were harvested from liquid cultures in exponential growth and spun down to give a concentrated cell suspension which was dispensed on the surface of SDM agar plates. On each day of incubation, the cells were washed off several plates and re-plated to assay the number of amoebae and cells committed to plasmodium development. The results showed that on a series of plates, each inoculated with a $0.01 \mathrm{ml}$ droplet containing $2 \times 10^{6}$ cells, the amoebae doubled in number in the first $2 \mathrm{~d}$ and formed committed cells which were first detectable in assays after $2 \mathrm{~d}$ incubation and visible as plasmodia in the cultures after $3 \mathrm{~d}$. Approximately $1 / 10^{3}$ of the cells assayed on days two and three were committed to plasmodium development. Amoebae inoculated on Millipore filters laid on grids over liquid SDM gave similar results but these cultures were more difficult to harvest and assay because the amoebae adhered to one another to form large cell sheets which were difficult to break up. Although the frequency of commitment was low, the large number of amoebae inoculated resulted in the formation of macroscopic plasmodia within a few days. No plasmodia were formed in surface cultures at $30^{\circ} \mathrm{C}$, indicating that committed cells were not present in the liquid cultures but were formed after the cells were placed on the axenic surface cultures at $26^{\circ} \mathrm{C}$.

These experiments showed that LU600 might be a suitable apogamic strain for some investigations of differential gene expression in amoebae and plasmodia cultured in axenic conditions. For the timing of changes in gene expression during the amoebal-plasmodial transition, however, a much higher frequency of commitment and more synchronous development will be required.

\section{Induction of flagellate formation in Axe amoebal strains}

In most amoebal strains growing on lawns of bacteria, rapid and efficient flagellate formation can be achieved by flooding the agar plates with water or various buffers (Pagh \& Adelman, 1982). Although amoebae grown in liquid axenic medium are damaged by osmotic shock if diluted directly into water, Blindt (1987) successfully developed a method that induced LU352 amoebae to form flagellates in axenic conditions. Using a modification of this method, all four selected Axe strains and CLd-AXE were tested for their ability to form flagellates (see Methods). The results (Table 4) showed that both LU353 and CLd-AXE failed to form flagellates; the cells swelled up and burst when diluted into water. In most tests, LU352, LU600 and LU381 gave high proportions of flagellates (Table 4). Some variations in morphology were observed, suggesting that some of the flagellates had not completed the transformation (Pagh \& Adelman, 1982); these variations have not been recorded in Table 4 since they were difficult to quantify and their frequencies showed poor repeatability in replicate tests. There was a slight decrease in the frequency of flagellates in LU352 when it was tested after 28 subcultures, but the other strains showed no consistent trends.

To investigate whether LU353 and CLd-AXE could form flagellates when cultured on bacteria, the amoebae were washed directly into water from bacterial lawns; this method was successful in inducing flagellate formation in all four Axe strains tested (Table 4). The frequencies of flagellates obtained from the bacterial cultures were slightly lower for LU353 and CLd-AXE than for LU352 and LU381, and a lower proportion of the flagellates in the former strains had normal morphology, but the extreme effects caused by diluting the amoebae into water from axenic cultures were not seen. Thus the difference in flagellate formation between the strains may possibly be caused by their difference in sensitivity to osmotic shock when cultured in liquid axenic medium. Subsequent attempts to induce flagellate formation in LU353 in axenic conditions in which the cells were protected from osmotic shock have so far been unsuccessful, however. Tests on samples of progeny isolated from the cross LU352 $\times$ LU353 have indicated that about $50 \%$ of the progeny resemble LU353 in their sensitivity to osmotic shock but that only some of the remaining progeny form flagellates as efficiently as LU352. Thus there may be more than one genetic factor affecting flagellate formation in LU353 amoebae cultured in axenic conditions.

The development by Blindt (1987) of a method to induce flagellate formation in LU352 in liquid axenic conditions has already proved valuable for biochemical studies of tubulins (Sasse $e t$ 
Table 4. Amoeba-flagellate transformation in selected Axe strains

Amoebae from liquid axenic cultures were tested for their ability to form flagellates on three occasions during the prolonged period of subculturing. The subculture used for each strain was as follows: (I) LU353, 2nd; LU381, 5th; other strains, 4th; (II) LU352 and LU600, 10th; LU381, 12th; (III) LU352 and LU600, 28th; LU381, 23rd.

\begin{tabular}{|c|c|c|c|c|}
\hline \multirow[b]{3}{*}{$\begin{array}{c}\text { Strain } \\
\text { (subline) }\end{array}$} & \multicolumn{4}{|c|}{ Percentage of flagellates (total cells scored)* } \\
\hline & \multicolumn{3}{|c|}{ Cultures from liquid axenic medium } & \multirow{2}{*}{$\begin{array}{c}\begin{array}{c}\text { Cultures } \\
\text { from } \\
\text { bacterial } \\
\text { lawns }\end{array} \\
\text { P }\end{array}$} \\
\hline & $\overbrace{}^{I}$ & $\overbrace{}^{\text {II }}$ & $\overbrace{}^{\text {III }}$ & \\
\hline $\begin{array}{r}\text { LU352 (i) } \\
\text { (ii) }\end{array}$ & $\begin{array}{l}86 \cdot 1(281) \\
84 \cdot 0(262)\end{array}$ & $\begin{array}{l}77.8(338) \\
81.4(295)\end{array}$ & $\begin{array}{l}66 \cdot 4(259) \\
53 \cdot 2(222)\end{array}$ & $93 \cdot 8(210)$ \\
\hline $\begin{array}{l}\text { LU600 (i) } \\
\text { (ii) }\end{array}$ & $\begin{array}{l}90 \cdot 4(229) \\
86 \cdot 9(268)\end{array}$ & $\begin{array}{l}83 \cdot 3(294) \\
69 \cdot 9(309)\end{array}$ & $\begin{array}{l}88 \cdot 1(329) \\
87 \cdot 6(217)\end{array}$ & - \\
\hline $\begin{array}{l}\text { LU353 (i) } \\
\text { (ii) }\end{array}$ & $\begin{array}{ll}0 & (301) \\
0 & (217)\end{array}$ & $\begin{array}{l}- \\
-\end{array}$ & $\begin{array}{l}- \\
-\end{array}$ & $61 \cdot 7(240)$ \\
\hline $\begin{array}{l}\text { LU381 (i) } \\
\text { (ii) }\end{array}$ & $\begin{array}{l}57 \cdot 3(239) \\
77 \cdot 4(248)\end{array}$ & $\begin{array}{l}71 \cdot 3(251) \\
77 \cdot 0(200)\end{array}$ & $\begin{array}{l}92 \cdot 7(246) \\
62 \cdot 1(203)\end{array}$ & $86 \cdot 6(292)$ \\
\hline $\begin{array}{l}\text { CLd-AXE (i) } \\
\text { (ii) }\end{array}$ & $\begin{array}{ll}0 & (243) \\
0 & (250)\end{array}$ & $\begin{array}{l}- \\
-\end{array}$ & $\begin{array}{l}- \\
-\end{array}$ & $72 \cdot 5(222)$ \\
\hline
\end{tabular}

- , Not tested.

* All cells with flagella are included, regardless of morphology. Encysted cells are not included in total.

al., 1987). Observations on long-term axenic cultures of LU352 amoebae have suggested, however, that even this strain may lose the ability to form flagellates if cultured continuously in liquid medium (M. Glyn and K. Gull, personal communication). It may therefore be necessary to re-initiate axenic cultures frequently from frozen stocks if this property is to be retained. For the construction of further strains able to undergo the amoeba-flagellate transformation in axenic conditions, it will be desirable to understand more fully the characteristics inherited in LU353 and its progeny, and work is in progress towards this end.

\section{Tests of diploid amoebae heterozygous and homozygous for the genes controlling growth in axenic medium}

Three strains of diploid amoebae (RA681-683), assumed to be heterozygous for axe alleles, were isolated from mixtures of amoebae of strains LU352 and OX112, a strain unable to grow in axenic medium, by the method described by Anderson \& Youngman (1985). Cultures of diploid amoebae assumed to be homozygous for axe alleles were isolated from LU352 and OX112 cultures treated with isopropyl $N$-(3-chlorophenyl)carbamate (CIPC) by the procedures described by Dee \& Anderson (1984). Two putative diploid strains (RA684-5) were isolated from LU352 and two (RA686-7) from OX112. The nuclear DNA contents of all seven selected strains were checked by flow cytometry (Fig. 5). As expected, the major peak for each strain was at approximately twice the fluorescence value of the major peaks in the two haploid strains. Although all cells were expected to be encysted and in G2 phase like the cultures shown in Fig. $4(\mathrm{c})$, about $20 \%$ of cells in the diploid strains gave fluorescence values which suggested that they might be aneuploid or in the S phase preceding encystment (Fry \& Matthews, 1987).

All seven diploid strains were inoculated in liquid axenic medium directly from lawns of live E. coli (see Methods) and their growth was compared with that of LU352 and OX112. As expected, OX112 and its homozygous diploid derivatives showed no growth. All three heterozygous strains also failed to grow, showing less than one doubling during the entire period of incubation ( $24 \mathrm{~d}$ ). During this period, LU352 amoebae grew as expected and were subcultured twice; the doubling time was $36 \mathrm{~h}$ in the first subculture and $30 \mathrm{~h}$ in the second. The homozygous diploid amoebae derived from LU352 also grew, but more slowly than the haploid strain; doubling times for the first subculture of RA684 and RA685 were $66 \mathrm{~h}$ and $132 \mathrm{~h}$ respectively. The growth tests were repeated several times and similar results were obtained. 

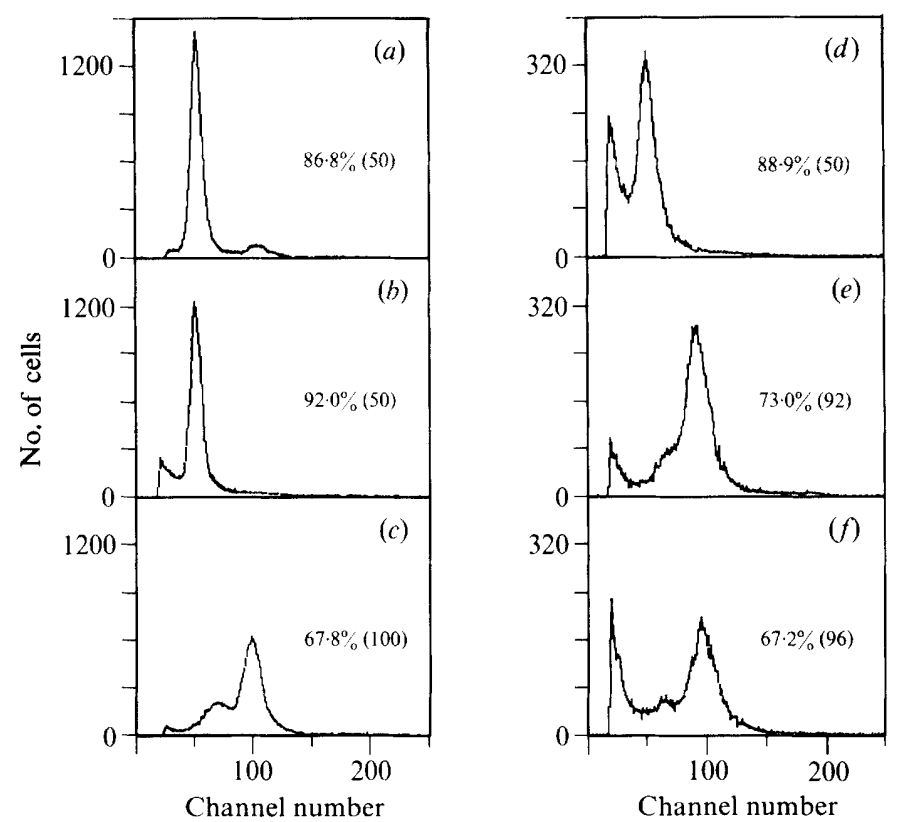

Fig. 5. DNA content of putative diploid amoebal strains measured by flow cytometry. Amoebal cell suspensions were made from cultures on bacterial lawns and stained with mithramycin. A threshold value for detection of fluorescence was chosen that would exclude measurement of bacteria and cell debris in the lowest fluorescence channels. On each panel the percentage of cells in the main peak (modal channel number in parentheses) is indicated. See text for further comments on distributions. (a) LU352, haploid Axe control strain; (b) OX112, haploid non-Axe control strain; (c) RA681, putative diploid amoebal strain synthesized from LU352 and OX112; $(d)$ LU352; $(e)$ RA684, putative diploid amoebal strain isolated after CIPC treatment of LU352; $(f)$ RA686, putative diploid amoebal strain isolated after CIPC treatment of OX112. Channel numbers are directly proportional to DNA content.

Since the heterozygous (axe/axe $e^{+}$strains failed to grow, it was concluded that at least one gene required for growth in axenic medium was recessive. To confirm that the genotype of the presumed heterozygotes was as expected, plasmodia were obtained from one of these strains (RA681) and progeny were isolated. A sample of 48 progeny clones, classified for mat $B$, matC, whi $A$ and fus $A$, showed the expected segregation and free recombination of these markers. When tested for growth in liquid axenic medium, by the method used for the diploid strains, 10 of the 48 clones grew in the first test and through several subcultures. Some of these strains grew as fast as LU352 and the range of doubling times was similar to that observed among progeny of the cross LU352 $\times$ LU481. These results confirmed that the gene or genes determining the Axe phenotype in LU352 were present in a heterozygous state in the RA681 diploid amoebae, where they were not expressed.

Genetic basis of growth in liquid axenic medium

Identification of the Axe phenotype. Genetic analysis of crosses involving Axe strains has been complicated by uncertainty about how the progeny should be classified. Because of the variation in growth rates, it was possible that there might be distinct classes of 'good' and 'poor' growers among the progeny, and that these might carry different major genes affecting different aspects of cell physiology. Repeated growth tests on Axe strains from several different crosses have indicated, however, that much of the variation seen within a set of progeny is probably due to factors associated with the test procedures. Most strains show increased growth rates in liquid medium after the first two subcultures and it does not seem likely that these changes are usually due to changes in the genetic constitution of the cells. One possible reason for the apparent change in growth rate is that when amoebae are inoculated into liquid medium from a culture on 
formalin-killed bacteria, many cells fail to grow or survive so that the inoculum of viable cells is much lower than it is estimated to be from the haemacytometer counts. Although the initial culture is never used to estimate growth rate, the inocula of viable cells in the first and second subcultures may again be smaller than estimated, particularly when only a small increase has been observed, since such cultures are only diluted by a small amount to maintain the cell density at $5 \times 10^{5} \mathrm{ml}^{-1}$. It has been shown in this paper that liquid cultures can be established from very small numbers of cells, and it is therefore possible that many of the apparent changes in growth rate are due to a small number of viable Axe cells gradually replacing a larger number of inviable cells that have been carried over from one subculture to the next in the early stages of testing. It would obviously be preferable to base the classification of Axe progeny on the second or third subculture, but this process was not adopted in all the crosses analysed in the present work since the main aim was to isolate new Axe strains, rather than to investigate fully the genetic basis of growth in axenic medium.

The 'low inoculum' effect described above will also give an impression of slow growth if the culture on bacteria contains a mixture of cells, resulting, for example, from genetic instability of a progeny clone due to ploidy change or mutation. Most sets of progeny clones from $P$. polycephalum crosses include a proportion of aneuploid or diploid strains which probably arise during meiosis (Adler \& Holt, 1975). Some such progeny are often detected as a result of their unusual selfing behaviour when spores are plated but others are not detected until plasmodial fusion tests reveal that they are heterozygous for the co-dominant fus $A$ alleles. It is therefore likely that some remain undetected during the classification of progeny and, in the crosses involving one Axe parent, these may include heterozygotes for the axe genes. Since the result described in the previous section indicated that axe genes are recessive, such aneuploids may be classified as non-growers in axenic medium; if they were unstable, however, they might give apparently slow or variable growth while the aneuploid cells were gradually replaced by haploid Axe amoebae.

Diploid amoebae can also arise in clones cultured on bacteria (Adler \& Holt, 1974a) and it seems likely that the diploid culture of LU381 detected by flow cytometry (Fig. $4 c$ ) arose in this way. It is hard to understand how diploids can replace haploid cells in an actively growing culture since they normally grow more slowly, even on bacteria; it is possible that they have some advantage during storage of cultures, however. Diploids formed in an Axe strain will be homozygous for the axe genes, but the tests of diploid strains constructed in the present work showed that homozygotes grew less well in liquid axenic medium than the haploid amoebae from which they were derived. If a mixed population of cells from a culture on bacteria is inoculated into liquid medium, diploid or aneuploid cells may be gradually replaced by haploid cells, giving an initial impression of very slow growth and an improved growth rate in later subcultures. Such a sequence of events probably accounts for the results obtained with LU381 (Table 3), where the doubling time changed from 80 to $40 \mathrm{~h}$ between the first and third subcultures.

Mixed and unstable clones may also result from reversion of the axe mutations, particularly if the mutant Axe amoebae suffer some selective disadvantage when cultured on bacteria. Although the plating tests indicated that Axe and non-Axe strains grew at nearly the same rate on bacterial lawns, there is some evidence that Axe mutant amoebae or cysts may survive less well when cultures on bacteria are stored at $4{ }^{\circ} \mathrm{C}$. When sets of progeny from several different crosses were stored in this way and later re-tested in liquid axenic medium, some clones previously classified as Axe were found to grow very poorly or not at all.

Any of the above factors may contribute to the small proportion of progeny clones observed in each cross that showed very slow or variable growth when tested in liquid axenic medium (e.g. doubling times over $70 \mathrm{~h}$ in Fig. 1 and 'doubtful' clones in Table 2). The majority of progeny clones classified as Axe in the crosses, however, gave doubling times that varied over a narrower range (usually less than $70 \mathrm{~h}$ ) and as discussed in a previous section, the results of re-testing and crossing some of these clones suggested that they belonged to a single homogeneous group and shared the same genotype for the major gene or genes determining growth in axenic medium. A characteristic such as growth rate is of course expected to show some continuous variation due to 
minor genetic and environmental factors, and it seems likely that the variation among these Axe strains can be attributed to such causes.

Number of 'axe' genes. Although the data in this paper seem to support the assumption that the Axe phenotype represents a single genotypic class, the number of major axe genes involved remains unclear. Some crosses between CLd-AXE and non-Axe strains are consistent with the hypothesis that two unlinked genes may be required for the Axe phenotype as originally reported (McCullough et al., 1978) whereas other crosses support a one-gene model (see Table 2). Although fuller genetic analysis will be necessary to resolve this question, the results of two crosses reported in the present paper are consistent with previous reports of crosses involving the same strains: the cross CLd-AXE $\times$ LU862 has repeatedly given approximately $25 \%$ Axe progeny whereas CLd-AXE $\times$ LU213 has repeatedly given $50 \%$ Axe progeny (J. Gorman, personal communication; McCullough et al., 1978). These results suggest that alleles of a gene affecting the ability to survive or grow in liquid axenic medium may be segregating among the non-Axe strains. Although laboratory strains of $P$. polycephalum have been made partially isogenic by programmes of back-crossing, they were originally derived from two separate natural isolates (Dee, 1982). It is possible that, due to their common origin, CLd and LU213 share the same allele at one locus and that CLd-AXE has a mutation at a second, unlinked locus; LU862, which is derived from a different natural isolate (Anderson \& Dee, 1977) would carry neither of these mutations. When the derivation of the strains is examined, the results of all the Axe $\times$ non-Axe crosses are consistent with this hypothesis, with the exception of LU381 $\times$ CLd; but here the genetic instability of LU381 may be a complicating factor. In summary, the genetic analysis is still insufficient to provide clear evidence of the number of mutations required to give an Axe phenotype but it is likely that not more than two loci are involved.

Molecular basis of growth in axenic medium. Since no ways have been found of detecting the Axe phenotype other than growth tests in liquid medium, there are no clues to its cellular or molecular basis. One possibility is suggested by the fact that Axe amoebae grow in medium identical with that utilized by normal plasmodia; during the amoebal-plasmodial transition in wild-type (non-Axe) strains, the cells acquire the ability to grow in this medium at about the same time as they become committed to plasmodium development (Blindt et al., 1986). Thus, Axe amoebal strains may carry a mutation allowing the expression of genes that are normally plasmodium-specific. Another possibility is that the axe mutations have some general or specific effect on cell permeability; Axe cells certainly seem to be in a more permeable state when growing in liquid medium than is normal for amoebae in suspension. Although it was originally supposed that the Axe phenotype might involve a loss of the natural tendency of amoebae to form non-feeding flagellates when suspended in liquids, the results in the present paper do not support this idea. At least some Axe strains have been identified that can be induced either to grow or to undergo the amoeba-flagellate transformation in liquid, axenic conditions, depending on the composition of the medium in which they are suspended. Although axenic conditions for flagellate formation by other Axe strains (e.g. LU353) have not yet been identified, the results suggest that such strains are deficient in their resistance to osmotic shock rather than in their ability to undergo the transformation.

We are grateful to Adrian Blindt, Darin Coulson, Jackie Price and Philip Watkins for help with some of the experiments, to Kamlesh Chandarana for help with figures and to the individuals cited in the test for permission to quote their unpublished results. For advice and assistance with the flow cytometry, we gratefully acknowledge John Lawry who ran our samples on the Sheffield University FACS machine purchased by Yorkshire Cancer Research Campaign.

\section{REFERENCES}

Adler, P. N. \& HolT, C. E. (1974a). Change in properties of Physarum polycephalum amoebae during extended culture. Journal of Bacteriology 120 , 532-533.

Adler, P. N. \& Holt, C. E. (1974b). Genetic analysis in the Colonia strain of Physarum polycephalum: heterothallic strains that mate with and are partially isogenic to the Colonia strain. Genetics 78, 1051-1062.

Adler, P. N. \& HolT, C. E. (1975). Mating type and the differentiated state in Physarum polycephalum. Developmental Biology 43, 240-253. 
ANDERson, R. W. (1977). A plasmodial colour mutation in the Myxomycete Physarum polycephalum. Genetical Research 30, 301-306.

Anderson, R. W. (1979). Complementation of amoebal-plasmodial transition mutants in Physarum polycephalum. Genetics 91, 409-419.

ANDERSON, R. W. \& DEE, J. (1977). Isolation and analysis of amoebal-plasmodial transition mutants in the Myxomycete Physarum polycephalum. Genetical Research 29, 21-34.

Anderson, R. W. \& Youngman, P. J. (1985). Complementation of $n p f$ mutations in diploid amoebae of Physarum polycephalum: the basis for a general method of complementation analysis at the amoebal stage. Genetical Research 45, 21-35.

Anderson, R. W., CoOKe, D. J. \& DeE, J. (1976). Apogamic development of plasmodia in the Myxomycete Physarum polycephalum: a cinematographic analysis. Protoplasma 89, 29-40.

Anderson, R. W., Burland, T. G. \& DeE, J. (1986). Genetic nomenclature for Physarum polycephalum. Physarum Newsletter 18(2), 2-5.

Bailey, J., ANDERSON, R. W. \& DeE, J. (1987). Growth and development in relation to the cell cycle in Physarum polycephalum. Protoplasma 141, 101-111.

BLINDT, A. B. (1987). Changes in cellular organization during apogamic development in Physarum polycephalum. PhD thesis, University of Leicester, UK.

Blindt, A. B., Chainey, A. M., Dee, J. \& Gull, K. (1986) Events in the amoebal-plasmodial transition of Physarum polycephalum studied by enrichment for committed cells. Protoplasma 132, 149-159.

Braun, R., Mittermayer, C. \& RusCh, H. P. (1965). Sequential temporal replication of DNA in Physarum polycephalum. Proceedings of the National Academy of Sciences of the United States of America 53, 924-931.

Burland, T. G., Chainey, A. M., Dee, J. \& Foxon, J. L. (1981). Analysis of development and growth in a mutant of Physarum polycephalum with defective cytokinesis. Developmental Biology 85, 26-38.

Burland, T. G., Gull, K., Schedl, T., Boston, R. S. \& Dove, W. F. (1983). Cell type-dependent expression of tubulins in Physarum. Journal of Cell Biology 97, 1852-1859.

Burland, T. G., Schedl, T., Gull, K. \& Dove, W. F. (1984). Genetic analysis of resistance to benzimidazoles in Physarum: differential expression of $\beta$-tubulin genes. Genetics 108, 123-141.

Chainey, A. M. (1981). Studies on the Myxomycete Physarum polycephalum. M.Phil. thesis, University of Leicester, UK.

COOKE, D. J. \& DEE, J. (1974). Plasmodium formation without change in nuclear DNA content in Physarum polycephalum. Genetical Research 23, 307-317.

COOKE, D. J. \& DEE, J. (1975). Methods for the isolation and analysis of plasmodial mutants in Physarum polycephalum. Genetical Research 24, 175-187.

DEE, J. (1966). Multiple alleles and other factors affecting plasmodium formation in the true slime mould Physarum polycephalum. Journal of Protozoology 13, 610-616.

DEE, J. (1978). A gene unlinked to mating-type affecting crossing between strains of Physarum polycephalum. Genetical Research 31, 85-92.
DeE, J. (1982). Genetics of Physarum polycephalum. In Cell Biology of Physarum and Didymium, vol. 1, pp. 211-251. Edited by H. C. Aldrich \& J. W. Daniel. New York: Academic Press.

DEE, J. (1986). The culture of Physarum amoebae in axenic media. In The Molecular Biology of Physarum polycephalum, pp. 253-269. Edited by W. F. Dove, J. Dee, S. Hatano, F. B. Haugli \& K.-E. WohlfarthBottermann. New York: Plenum Press.

DEE, J. \& ANDERSON, R. W. (1984). The effect of ploidy on the stability of plasmodial heterokaryons in Physarum polycephalum. Journal of General Microbiology 131, 1167-1179.

Dove, W. F., Dee, J., Hatano, S., Haugli, F. B. \& WOHLFARTH-BotTERMANN, K.-E. (1986). The Molecular Biology of Physarum polycephalum. New York: Plenum Press.

Foster, K. E., Burland, T. G. \& Gull, K. (1987). A mutant $\beta$-tubulin confers resistance to the action of benzimidazole-carbamate microtubule inhibitors both in vivo and in vitro. European Journal of Biochemistry 163, 449-455.

FRY, J. \& MatTHEws, H. R. (1987). Flow cytometry of the differentiation of Physarum polycephalum myxamoebae to cysts. Experimental Cell Research 168, 173-181.

Goodman, E. M. (1972). Axenic culture of myxamoebae of the Myxomycete Physarum polycephalum. Journal of Bacteriology 111, 242-247.

Gorman, J. A., Dove, W. F. \& Shaibe, E. (1979). Mutations affecting the initiation of plasmodial development in Physarum polycephalum. Developmental Genetics 1, 47-60.

Gull, K., Birkett, C. R., Blindt, A. B., Dee, J., Foster, K. E. \& PaUl, E. C. A. (1985). Expression of a multi-tubulin family and the in vivo assembly of microtubular organelles in Physarum polycephalum. In Microtubules and Microtubule Inhibitors. Edited by M. DeBrabander \& J. De Mey. Amsterdam: Elsevier Science Publishers.

Havercroft, J. C. \& Gull, K. (1983). Demonstration of different patterns of microtubule organization in Physarum polycephalum myxamoebae and plasmodia using immunofluorescence microscopy. European Journal of Cell Biology 32, 67-74.

KaWANo, S., Kuroiwa, T. \& ANDERSON, R. W. (1987). A third multiallelic mating-type locus in Physarum polycephalum. Journal of General Microbiology 133, 2539-2546.

McCullough, C. H. R. \& DeE, J. (1976). Defined and semi-defined media for the growth of amoebae of Physarum polycephalum. Journal of General Microbiology 95, 151-158.

McCullough, C. H. R., DeE, J. \& Foxon, J. L. (1978). Genetic factors determining the growth of Physarum polycephalum amoebae in axenic medium. Journal of General Microbiology 106, 297-306.

MOHBERG, J. \& RUSCH, H. P. (1971). Isolation and DNA content of nuclei of Physarum polycephalum. Experimental Cell Research 66, 305-316.

MohberG, J., BABCOCK, K. L., Haugli, F. B. \& Rusch, H. P. (1973). Nuclear DNA content and chromosome numbers in the Myxomycete Physarum polycephalum. Developmental Biology 34, 228-245.

PAGH, K. \& Adelman, M. R. (1982). Identification of a microfilament-enriched, motile domain in amoebo- 
flagellates of Physarum polycephalum. Journal of Cell Science 54, 1-21.

Poulter, R. T. M. \& DEE, J. (1968). Segregation of factors controlling fusion between plasmodia of the true slime mould Physarum polycephalum. Genetical Research 12, 71-79.

Roobol, A., Pogson, C. I. \& Guld, K. (1980). In vitro assembly of microtubule proteins from myxamoebae of Physarum polycephalum. Experimental Cell Research 130, 203-215.

Sasse, R., Glyn, M. C. P., Birkett, C. R. \& Gull, K. (1987). Acetylated $\beta$-tubulin in Physarum: immunological characterization of the isotype and its usage in particular microtubular organelles. Journal of Cell Biology 104, 41-49.

Shinnick, T. M., Pallotta, D. J., Jones-Brown, Y. R., Youngman, P. J. \& Holt, C. E. (1978). A gene, imz, affecting the $\mathrm{pH}$ sensitivity of zygote formation in Physarum polycephalum. Current Microbiology 1, 163-166.

SWeEnEY, G. E., Watts, D. I. \& TuRnock, G. (1987). Differential gene expression during the amoebalplasmodial transition in Physarum. Nucleic Acids Research 15, 933-945.

Turner, H. M., Mohberg, J. \& Goodman, E. M.
(1981). A flow cytometry study of the cell cycle and of ploidy levels in Physarum polycephalum myxamoebae and plasmodia. Microbios 32, 29-36.

WENRICK, D. H. \& DilleR, W. F. (1950). In McClung's Handbook of Microscopical Technique for Workers in Animal and Plant Tissues, pp. 432-476. Edited by R. McClung Jones. London: Cassell.

WheALs, A. E. (1970). A homothallic strain of the Myxomycete Physarum polycephalum. Genetics 66, 623-633.

Youngman, P. J., Adler, P. N., Shinnick, T. M. \& HolT, C. E. (1977). An extracellular inducer of asexual plasmodium formation in Physarum polycephalum. Proceedings of the National Academy of Sciences of the United States of America 74, 1120-1124.

Youngman, P. J., Pallotta, D. J., Hosler, B., Struhl, G. \& Holt, C. E. (1979). A new mating compatibility locus in Physarum polycephalum. Genetics 91, 683-693.

Youngman, P. J., Anderson, R. W. \& Holt, C. E. (1981). Two multiallelic mating compatibility loci separately regulate zygote formation and zygote differentiation in the Myxomycete Physarum polycephalum. Genetics 97, 513-530. 